NoTE

\title{
The Medical Resident Working Hours Debate: A Proposal for Private Decentralized Regulation of Graduate Medical Education
}

\author{
Anthony Ciolli*
}

\section{INTRODUCTION}

The debate over the regulation of resident working hours has been one of the most significant recent controversies in graduate medical education. A diverse array of organizations, including Congress, state governments, administrative agencies, and the Accreditation Council for Graduate Medical Education (ACGME), have had to confront this issue at some point over the past two decades. While a consensus has developed that at least some aspects of resident working conditions should be regulated in order to enhance patient safety, there remains an ongoing controversy over which organizations should implement and oversee these regulations.

This Note examines and evaluates the costs and benefits of allowing certain bodies to regulate physician residency programs. Although most scholarship has promoted regulation either by governmental entities, the ACGME, or residents themselves, none of these groups is suited to this task. This Note argues that the ideal regulatory system should involve a decentralized private sector approach, achieved by ending the ACGME monopoly over graduate medical education accreditation and allowing for multiple accrediting agencies. Switching to a private decentralized system would allow for greater experimentation, which would increase the likelihood of discovering the best way to regulate resident

* J.D. candidate, University of Pennsylvania Law School; A.L.M. candidate, Harvard University; M.Bioethics candidate, University of Pennsylvania Medical School. I would like to thank Kristin Madison, Andrew Morriss, Gideon Parchomovsky, and Eugene Volokh for their continued inspiration and support. 
working conditions to enhance patient safety.

\section{PURPOSES OF RESIDENT WORK HOUR REGULATION}

Although a consensus has emerged that residents have traditionally worked an unacceptable number of hours per week, ${ }^{1}$ the individuals and organizations that support resident work hour limitations do so for different reasons. Three of the primary reasons are patient safety, resident health and quality of life, and residency program educational quality.

\section{A. Patient Safety}

The most common, and perhaps most compelling, argument for resident work hour regulation deals with a potential externality caused by long work hours: decreased patient care quality. Multiple studies have shown that sleep loss and fatigue adversely affect resident performance. An early study, conducted in 1972, found that sleep-deprived surgical residents were more likely to make poorly planned maneuvers. ${ }^{2}$ Later studies have reported similar findings. One 1998 study of surgical residents found that sleep-deprived residents made twenty percent more errors and took fourteen percent more time to complete tasks; ${ }^{3}$ a 2001 study with a larger sample size found that sleep deprivation resulted in an approximately two-fold increase in errors and approximately thirty-eight percent more time to complete tasks. ${ }^{4}$

Researchers examining non-surgical residents found similar results. Two early studies found that residents tested after a rested night made almost half as many errors as residents who suffered sleep loss, ${ }^{5}$ and that junior physicians' reasoning test scores reliably deteriorated with eight hours of cumulative sleep debt. $^{6}$ Various later studies have found that long hours of work in non-surgical

1. See infra Sections II.B-C (providing an overview of current attitudes toward resident work hour regulations).

2. Leonard I. Goldman et al., Stresses Affecting Surgical Performance and Learning: Correlation of Heart Rate, Electrocardiogram and Operation Simultaneously Recorded on Videotapes, 12 J. SuRGICAL RES. 83, 84-85 (1972).

3. N.J. Taffinder et al., Effect of Sleep Deprivation on Surgeons' Dexterity on Laparoscopy Simulator, 352 LANCET 1191, 1191 (1998).

4. Teodor P. Grantcharov et al., Laparoscopic Performance After One Night on Call in a Surgical Department: Prospective Study, 323 BRIT. MED. J. 1222, 1222-23 (2001).

5. Richard C. Friedman et al., The Intern and Sleep Loss, 285 NEw ENG. J. Med. 201, 202 (1971).

6. E.C. Poulton et al., The Performance of Junior Hospital Doctors Following Reduced Sleep and Long Hours of Work, 21 ERGOMETRICS 279, 279 (1978). 
residents results in a significant deterioration in reaction time, ${ }^{7}$ significant impairment in cognitive function, ${ }^{8}$ and reduction in short-term recall. ${ }^{9}$ Another study, focusing on internal medicine residents, found that increased total sleep time resulted in twenty-five percent fewer medication errors. ${ }^{10}$ A more recent study, which randomly assigned internal medicine interns working in intensive care units to "traditional" (including twenty-four hour or more work shifts) and "intervention" (no extended work shifts and fewer hours worked per week) schedules, found that those on the traditional schedule made nearly forty percent more serious medical errors than those on the intervention schedule and 5.6 times more serious diagnostic errors. ${ }^{11}$ Since sleepy residents could put patients at a greater risk of injury or even death, and since many hospitals have not attempted to remedy the problem on their own, some have argued that an external entity should step in and regulate resident work hours in order to protect the safety of patients. ${ }^{12}$

\section{B. Resident Health and Quality of Life}

Others have argued that resident work hours should be regulated due to the detrimental impact long hours and sleep deprivation may have on residents themselves. Many studies have shown that working conditions have had negative effects on residents' health. One study found a connection between sleep and emotional health; surgical residents who experienced sleep loss were significantly more likely to feel angry, confused, and fatigued..$^{13}$ An additional study reported that residents suffered from increased stress and depression. ${ }^{14} \mathrm{~A}$ more recent study found that seventy-six percent of residents in an internal medicine program suffered from a condition called "burnout," a condition characterized by "depersonalization, emotional exhaustion, and a sense of low

7. D.I. Orton \& J.H. Gruzelier, Adverse Changes in Mood and Cognition Performance of House Officers After Night Duty, 298 BRIT. MED. J. 21, 22 (1989).

8. John Robbins \& Fred Gottlieb, Sleep Deprivation and Cognitive Testing in Internal Medicine House Staff, 12 W.J. MED. 82, 84-85 (1990).

9. Ian J. Deary \& Rosemary Tait, Effects of Sleep Disruption on Cognitive Performance and Mood in Medical House Officers, 295 BRIT. MED. J. 1513, 1514-15 (1987).

10. Daniel J. Gottlieb et al., Effect of a Change in Housestaff Work Schedule on Resource Utilization and Patient Care, 151 ARChIVEs InTERnal MED. 2065, 2068 (1991).

11. Christopher P. Landrigan et al., Effect of Reducing Interns' Work Hours on Serious Medical Errors in Intensive Care Units, 351 NEW ENG. J. MED. 1838, 1842-43 (2004).

12. See infra Section II.B.

13. Edward J. Bartle et al., The Effects of Acute Sleep Deprivation During Residency Training, 104 SuRGERY 311, 314 (1988).

14. David B. Reuben, Psychologic Effects of Residency, 76 S. MED. J. 380 (1983). 
personal accomplishment."15 The authors hypothesized that burnout may also contribute to "increases in cynicism and decreases in compassion.",

Evidence also shows that long hours may have a negative impact on the physical health of residents. One study, for instance, found that sleep-deprived residents suffered from greater complications during pregnancy, though this difference lost significance when controlling for socio-economic status and medical sophistication. ${ }^{17}$ In $1988,{ }^{18} 1996,{ }^{19} 1997,{ }^{20}$ and $1999,{ }^{21}$ four authors noted that residents suffering from sleep loss are at a significantly greater risk of being in a motor vehicle accident. The most recent motor vehicle study, published in 2005, reports that working extended shifts significantly increases the risk that an intern will fall asleep while driving or while stopped in traffic, and every extended work shift increases an intern's chance of being involved in a motor vehicle accident during the commute from work by over sixteen percent. ${ }^{22}$

Several studies have shown that residents' social health and overall quality of life is impaired due to long work hours. A 1993 study found that work hour reductions increased resident satisfaction by allowing them to spend more time with their families. ${ }^{23}$ Another study found that work hour limitations improved the quality of residents' personal lives and relationships. ${ }^{24}$ A 2004 study that compared a traditional system to a new (two shift) system found that residents' spouses rated residents' abilities to attend family events significantly improved

15. Tait D. Shanafelt et al., Burnout and Self-Reported Patient Care in an Internal Medicine Residency Program, 136 AnNals InTERnal Med. 358, 358 (2002).

16. Id. at 366.

17. L.M. Osborn et al., Outcomes of Pregnancies Experienced During Residency, 31 J. FAM. PRAC. 618 (1990).

18. James Robert Wendt \& Lester J. Yen, The Resident by Moonlight: A Misguided Missile, 259 JAMA 43 (1988).

19. Carole L. Marcus \& Gerald M. Loughlin, Effect of Sleep Deprivation on Driving Safety in Housestaff, 19 SLEEP 763, 765 (1996).

20. R.T. Geer et al., Incidence of Automobile Accidents Involving Anesthesia Residents After On-Call Duty Cycles, 87 ANESTHESIOLOGY A938 (1997).

21. Mark T. Steele et al., The Occupational Risk of Motor Vehicle Collisions for Emergency Medicine Residents, 610 ACAD. EMERGENCY MED. 1050, 1052 (1999).

22. Laura K. Barger et al., Extended Work Shifts and the Risk of Motor Vehicle Crashes Among Interns, 352 NEw ENG. J. MED. 125, 125 (2005).

23. Joseph Conigliaro et al., Internal Medicine Housestaff and Attending Physician Perceptions of the Impact of the New York State Section 405 Regulations on Working Conditions and Supervision of Residents in Two Training Programs, 8 J. Gen. InTERnal Med. 502, 505 (1993).

24. Amelia Kelly et al., The Effect of New York State Restrictions on Resident Work Hours, 78 OBSTETRICS \& GYNECOLOGY 468, 468 (1991). 
after the change to the two shift system. ${ }^{25}$ Yet another recently published study reports that there is a relationship between hours worked and a resident's happiness and ability to take care of responsibilities outside of work. ${ }^{26}$

\section{Residency Program Educational Quality}

Still others have proposed that resident work hours be regulated in order to improve the educational quality of residency programs. By reducing hours, some believe that residents will benefit more from the hours they do spend at work. In one experiment, where average work hours were reduced from 110 hours a week to 75 hours a week, many residents felt that overall educational quality improved, although faculty believed that, on average, there was no change. ${ }^{27}$ Another study found that work hour reductions allowed residents to have more time for reading as well as for preparing for conferences and cases. ${ }^{28}$

Some, however, have argued that the largest gains in educational quality are achieved when hours spent performing administrative or ancillary functions often referred to as "scut work" - are reduced. ${ }^{29}$ Several studies support this claim. In one study, where health technicians were added to surgical teams, resident work hours dropped from an average of 16.3 per weekday to 12.9 per weekday; however, resident hours spent in the operating room increased from 3.3 hours per week to 9.8 hours per week. ${ }^{30}$

Medical student and resident advocacy groups, such as the American Medical Student Association, support work hour limits primarily to "protect resident physicians from overwork,"31 although such organizations believe "an

25. The two shift system involved dividing residents into a day shift and a night shift. M.J. Goldstein et al., A 360 Degrees Evaluation of a Night-Float System for General Surgery: A Response to Mandated Work-Hours Reduction, 61 CURRENT SURGERY 445, 448 (2004).

26. Kara C. Kort et al., Resident Perceptions of the Impact of Work-Hour Restrictions on Health Care Delivery and Surgical Education: Time for Transformational Change, 136 SURGERY 861, 864-65 (2004).

27. Kelly et al., supra note 24 , at 470 .

28. Chandrasekhar Bob Basu et al., The Effect of the Accreditation Council for Graduate Medical Education Duty Hours Policy on Plastic Surgery Resident Education and Patient Care: An Outcomes Study, 114 Plastic \& ReCONSTRUCTIVE SURGERY 1878, 1881 (2004).

29. Some current and former residents despise "scut work" to such an extent that they participate on interactive websites in order to inform prospective applicants about the amount of "scut work" their programs require. See, e.g., Scutwork.com: Residency Program Reviews, http://www.Scutwork.com.

30. Yale D. Podnos et al., Reducing the Noneducational and Nonclinical Workload of the Surgical Resident: Defining the Role of the Health Technician, 60 CURRENT SURGERY 529, 530 (2003).

31. Am. Med. Student Ass'n, The Resident Work Hour Issue: Your Home for the Most Up-to- 
improved working environment" would also ensure patient safety. ${ }^{32}$ However, most proponents of work hour regulations, such as patient rights organizations, legislators, and the mass media, have placed a significantly greater emphasis on the patient safety. ${ }^{33}$ Thus, every attempt to limit resident work hours was made with that purpose in mind. ${ }^{34}$ The following Part provides a brief overview of the history of graduate medical education and attempts to regulate it by both government entities and the ACGME.

\section{GRAdUATE MEDICAL-EDUCATION: A BRIEF History}

The U.S. Department of Health and Human Services defines graduate medical education as "the process for providing academic and clinical education to physicians after they have graduated from an accredited medical school. ${ }^{, 35}$ Medical school graduates enroll in these programs in order to obtain advanced training in a specialty area, such as surgery. ${ }^{36}$. Such education typically takes place at teaching hospitals ${ }^{37}$ often affiliated with medical sçhools, ${ }^{38}$ which allows physician residents to provide patient care under the supervision of a teaching physician. ${ }^{39}$ While program lengths vary by specialty, typical residencies last from three to seven years. ${ }^{40}$

Formal residency programs have existed for almost 120 years. ${ }^{41}$ One can divide the regulatory history of resident work hour limits into three distinct eras: laissez-faire, New York State regulation, and ACGME self-regulation.

Date Information, http://www.amsa.org/rwh/ (last visited Dec. 9, 2006).

32. Id.

33. See infra Sections II.B-C (explaining why New York State and the ACGME ultimately chose to regulate resident work hours).

34. See infra Sections II.B-C.

35. NAT'L CTR. FOR HEALTH WORKFoRCE INFO. \& ANALYSIS, U.S. DeP'T OF Health \& HumaN Servs., Graduate Medical Education and Public Policy: A Primer 1 (2000) [hereinafter PRIMER].

36. Id. at 2 .

37. Id. at 1 .

38. More than ninety percent of all graduate medical education programs are affiliated with a medical school. Id. at 3 .

39. Id. at 2 .

40. Stewart R. Reuter, Professional Liability in Postgraduate Medical Education, 15 J. LeGal MED. 485, 485-86 (1994).

41. See Primer, supra note 35 , at 2 ("The first formal physician residency program ... was established at Johns Hopkins Hospital in Baltimore in 1889."). 


\section{A. The Laissez-Faire Period: "The Bad Old Days"}

The laissez-faire period spanned a century, from the first residency program established at Johns Hopkins Hospital in 1889 to the creation of New York State Department of Health regulations. The first half of the twentieth century marked graduate medical education's formative years. By the early 1900s, other institutions had already begun to create their own internship programs modeled after the Johns Hopkins system. ${ }^{42}$ Although such programs "had become an accepted part of preparation for general medical practice,",43 specialty training beyond basic one-year internships was largely unregulated until the early 1930s, when the American Board of Medical Specialties (ABMS) began to provide quality assurance by certifying specialists. ${ }^{44}$ Starting in the early 1970 s, a similar quality assurance function was performed by the Liaison Committee on Graduate Medical Education, which then evolved into the ACGME in 1981. ${ }^{45}$

Although some form of external oversight was present for much of this period, one must distinguish between regulation of educational quality and regulation of working conditions. The ACGME and its predecessor, while generally" encouraging hospitals to deemphasize "scut work" and maximize educational value, made little or no attempt to intervene in the relationship between a program and its residents. ${ }^{46}$

Residency programs, in the absence of outside regulations, were free to determine resident physician working conditions as they saw fit. During this period, a general consensus emerged that residents should work very long hours as part of their training. Researchers continue to debate whether this consensus was primarily motivated by economic or pedagogical reasons. ${ }^{47}$ There is little doubt that hospitals receive significant economic benefits from their residency programs - residents are an "elastic source of physician labor" 48 and have been

42. Id.

43. Id.

44. Id. Note that the ABMS did not accredit residency programs-it provided quality assurance by testing individuals after they completed a residency program. For more information on the certification procedure, see History of the ABMS, http://www.abms.org/About_ABMS/ who_we_are.aspx (last visited Dec. 9, 2006).

45. PRIMER, supra note 35.

46. See generally Lindsay Evans, Note, Regulatory and Legislative Attempts at Limiting Medical Resident Work Hours, 23 J. LEGAL MED. 251, 256-58 (2002) (discussing the ACGME's stance on the resident work hour issue prior to its decision to regulate work hours itself).

47. See, e.g., Jennifer F. Whetsell, Changing the Law, Changing the Culture: Rethinking the "Sleepy Resident" Problem, 12 ANNALs HEALth L. 23, 43-50 (2003) (discussing why the medical establishment has established and continues to support the traditional residency system).

48. David A. Asch \& Ruth M. Parker, The Libby Zion Case: One Step Forward or Two Steps 
"regularly exploited as a source of inexpensive labor" from as early as the $1920 \mathrm{~s} .{ }^{49}$ Even at the very best teaching hospitals, programs have been criticized for using residents to perform a significant number of ancillary or administrative functions that serve no educational purpose, such as drawing blood samples or transporting patients. ${ }^{50}$

While economic incentives exist for hospitals to have their residents work long hours, many have argued that such hours are also necessary for educational purposes. There has been a widespread belief that new physicians must experience a "round-the-clock trial by fire" as part of their training - an idea that is still deeply entrenched to this day. ${ }^{51}$ Doctors have historically believed that long working hours help residents to "learn to remain focused under taxing circumstances." ${ }^{, 52}$ According to these doctors, it is absolutely necessary for residents to experience sleep deprivation and other hardships, for they must learn to "subordinate their needs for sleep and food to the unpredictable and often consuming demands of patient care." $\$ 33$ As one doctor put it, "Patients get sick on Christmas Day. Ditto 2 o'clock in the morning, and as a physician you need to be able to take care of them." ${ }^{, 54}$ Long hours also serve a psychological function, in that they allow residents to solidify social identity and learn the humility necessary to assume a powerful social role. ${ }^{55}$ In other words, the medical establishment believes mental and physical toughness is vital to the practice of medicine, and graduate medical education programs "go to great lengths to test these residents' and interns' mettle." 56

However, long hours did not develop as mere fraternity-like hazing rituals.

Backward?, 318 New ENG. J. MED. 771, 774 (1988).

49. Kenneth M. Ludmerer \& Michael M. E. Johns, Reforming Graduate Medical Education, 294 JAMA 1083, 1084 (2005).

50. Id.

51. See Carl T. Hall, Doctors See Loopholes in Limits on Workweek, S.F. CHRON., June 16, 2002 , at A4.

52. Tom Pelton, New Rules on Residents Leave Hazy Prognosis for Hospitals, Balt. Sun., June 15,2002 , at $1 . A$.

53. Sandra G. Boodman, Waking Up to the Problem of Fatigue Among Medical Interns, L.A. Times, Apr. 16, 2001, at S1.

54. See Peter C. Beller, Your Intern Today is Both Sleepy and Bored. Feel Better?, N.Y. TimES, Sept. 14, 2005, at B9 (quoting Dr. James Rohack, former chairman of the American Medical Association).

55. See Leanord C. Groopman, Medical Internship as Moral Education: An Essay on the System of Training Physicians, 11 CULtural MEd. \& PsyChIATRY 207, 207-27 (1987) (suggesting that long hours are a rite of passage that promote group cohesion, establish social identity, and further other psychological goals).

56. Whetsell, supra note 47 , at 46. 
Unlike other educational programs, where students can study the subject matter outside of the physical educational institution, a medical resident's education cannot be duplicated outside of the hospital setting - residents attempting to specialize in surgery cannot simply go home and practice their surgical skills. In order to obtain advanced clinical training in their specialty, residents have no other option but to treat actual patients in an actual clinical setting, such as a teaching hospital; thus, residents seeking to obtain as much training as possible would often want to work longer hours to hone their skills. ${ }^{57}$

Work hours, while universally long, still differed from program to program during the laissez-faire period. The lack of regulation allowed different specialties and sub-specialties to develop their own work hour norms over time. Such norms were not arbitrary: They were highly correlated with the intensity of the specialization. While residents in surgery often worked as many as 130 hours a week, residents in other specialties have been known to work on average as little as 60 or 70 hours per week. ${ }^{58}$ In other words, complicated and difficult to master specialties demanded a greater time commitment from their residents than specialties that require less technical skill on the part of the resident. ${ }^{59}$

\section{B. New York State Regulation: A Failed Experiment}

Although some individuals expressed their concern about medical resident working hours during the laissez-faire period, no serious attempt was made to change the status quo. This began to change in the mid-1980s, when the death of an eighteen-year-old college freshman became the first step in a process that would result in the State of New York regulating resident working hours, and eventually brought about significant changes in graduate medical education nationwide.

57. Myrle Croasdale, Beat the Clock: The New Challenges to Residents, Am. Med. News, Mar. 8, 2004, available at http://www.ama-assn.org/amednews/2004/03/08/prsa0308.htm.

58. Scott Turner, Medical Residency: An Exercise in Sleep Deprivation, GeORGE ST. J., Oct. 4, 2001, available at $\mathrm{http}: / / \mathrm{www}$.brown.edu/Administration/George_Street_Journal/vol26/

26GSJ06h.html; $c f$. Richard W. Schwartz et al., Controllable Lifestyle: A New Factor in Career Choice by Medical Students, 64 ACAD. MED. 606 (1989) (discussing how some medical specialties are known to have better lifestyles than others).

59. A recent survey by MercuryMD shows that this is true even today - residents in specialties that involve the least amount of direct patient care, such as pathology and radiology, work between twenty to forty fewer hours per week on average than residents in specialties that involve greater patient care responsibilities, such as surgery and ob-gyn. MERCURYMD, IMPACT OF HOSPITAL COMPUTER SYSTEMS ON RESIDENT WORK HOURS, http://www.medrecinst.com/uploadedFiles/ resources/venResearch/resident(1).pdf (last visited Dec. 9, 2006). 


\section{The Desire To Regulate}

The desire to transition from a free market system to state regulation was based on the idea that allowing individual residency programs to set their own work hour norms resulted in a market failure, for the free market system could not properly handle the patient safety externality. ${ }^{60}$ Residency programs sought to train "tough" doctors whom the program could condition to become less dependent on sleep and used to working long and unpredictable hours; ${ }^{61}$ however, residents do not acquire these skills immediately, if they ever do. ${ }^{62}$ Since the typical residency programs provide residents with a very high degree of patient care responsibility at a very early stage in the program, ${ }^{63}$ some argued that residency programs, by requiring their residents to work very long hours, were putting patients at risk by placing their care in the hands of sleep-deprived residents. ${ }^{64}$ The death of Libby Zion confirmed these assumptions.

\section{The Libby Zion Incident}

On the evening of March 4, 1984, Libby Zion was admitted to New York Hospital with an earache and a 103 degree fever. ${ }^{65}$ Although Libby's medical team, consisting of two physically present residents and an attending physician only available by phone, ${ }^{66}$ had been specifically told she was taking Nardil, an anti-depressant, one of the residents prescribed an injection of Demerol, a drug fatal when taken in conjunction with Nardil. ${ }^{67}$ Libby immediately began to suffer an adverse reaction to Demerol. She thrashed about violently in bed and her fever rose, but she was not seen by any doctor for about four hours. The only attention she received was from attendants who restrained her on instructions from an

60. See supra Section I.A (discussing the potential impact long resident work hours may have on patient safety).

61. See Boodman, supra note 53.

62. Studies have shown that, contrary to popular belief, healthy adults cannot acclimate to sleep deprivation. See, e.g., Mark Blagrove et al., The Effects of Chronic Sleep Reduction on the Performance of Cognitive Tasks Sensitive to Sleep Deprivation, 9 APPLIED COGNITIVE PSYCHOL. 21 (1994); Mary A. Carskadon \& William C. Dement, Cumulative Effects of Sleep Restriction on Daytime Sleepiness, 18 Psychophysiology 107 (1981); David F. Dinges et al., Cumulative Sleepiness, Mood Disturbance, and Psychomotor Vigilance Performance Decrements During a Week of Sleep Restricted to 4-5 Hours Per Night, 20 SLEEP 267 (1997).

63. PRIMER, supra note 35 , at 2.

64. See supra Section I.A (discussing how sleepy residents may impair patient safety).

65. Tom Wicker, Doctors in the Dock?, N.Y. TiMES, Dec. 23, 1985, at A17.

66. Craig Horowitz, The Doctor Is Out, N.Y. MAG., Nov. 3, 2003, available at $\mathrm{http} / / /$ newyorkmetro.com/nymetro/health/features/n_9426/index $2 . \mathrm{html}$.

67. Wicker, supra note 65. 
intern who had never examined her. ${ }^{68}$ By morning, Libby had passed away. ${ }^{69}$

Sidney Zion, Libby's father and a former prosecutor and New York Times journalist, hired attorneys to investigate his daughter's death and was shocked to discover that both residents had been working at the hospital for eighteen hours or more by the time they saw Libby. ${ }^{70}$ Rather than merely suing the hospital for malpractice, Sidney Zion decided to use his influence to draw attention to the poor care patients may receive due to overworked and fatigued residents, ${ }^{71}$ he successfully lobbied for a grand jury investigation of New York Hospital's residency program. ${ }^{72}$ Although the grand jury did not issue any criminal indictments, it did provide several recommendations to improve patient care, including placing limits on medical resident working hours. ${ }^{73}$ In 1987 , the New York State Commissioner of Health appointed a committee, chaired by Dr. Bertrand Bell, to examine the grand jury's findings. ${ }^{74}$ This committee, dubbed the Bell Commission, recommended substantial changes to graduate medical education, most notably that the state government place limits on resident working hours. ${ }^{75}$

\section{State Regulation: Implementation and Enforcement}

New York adopted many of the Bell Commission's recommendations in 1988, making New York the first state to regulate resident working hours. ${ }^{76}$ These regulations, which went into effect in July 1989 and are still in effect today, limit residents to an eighty-hour workweek (averaged over a four-week period). ${ }^{77}$ In addition, residents cannot work more than twenty-four consecutive hours of scheduled work (twelve hours in emergency departments) and are required to receive at least eight hours between these work assignments. ${ }^{78}$ Furthermore, residents must receive a minimum of twenty-four nonworking

68. Id.

69. Id.

70. Horowitz, supra note 66.

71. Wicker, supra note 65.

72. Id.

73. Robert Steinbrock, The Debate Over Residents' Work Hours, 347 NEw ENG. J. MED. 1296, 1297 (2002).

74. Id.

75. Id.

76. Don Colburn, Young Doctor's Lack of Sleep Doesn't Affect Care, WASH. Post, Sept. 27, 1988 , at Z5.

77. Steinbrock, supra note 73.

78. Id. 
hours every week. ${ }^{79}$

At the time these regulations were adopted, many believed that other states would soon follow New York's lead and implement their own regulations. ${ }^{80}$ However, this never came to pass; even today, New York remains the only state to have instituted limits on resident work hours. Although four states California, Hawaii, Massachusetts, and Pennsylvania - have contemplated similar regulations, their bills never passed. ${ }^{81}$

The New York regulations, once warmly embraced and originally inspiring much optimism, soon became regarded as a failure due to hospitals largely ignoring the regulations. In 1989, the year the regulations went into effect, sixtytwo percent of New York hospitals failed to comply with at least one major provision; in 1991 this figure rose to seventy-one percent. By 1994 a full ninetytwo percent of hospitals were in non-compliance with the regulations. ${ }^{82}$ Three factors largely explain why non-compliance rates reached such high levels.

\section{a. Enforcement}

Perhaps the most obvious reason for lack of compliance with the New York regulations was the State's inability to effectively enforce them. First, New York's monitoring mechanisms were weak. When the regulations first went into effect in 1989, New York's Department of Health visited thirty New York City hospitals in order to assure their compliance with the new regulations. ${ }^{83}$ However, in 1993, this number dropped to only twelve visits. ${ }^{84}$ Insufficient funding likely caused this low level of monitoring; although the Department of Health was given the additional duty of enforcing these regulations, its budget was cut by both the New York State and New York City governments. ${ }^{85}$ Given the Department's other responsibilities, it should come as no surprise that the Department of Health did not view enforcing resident work hour regulations as a top priority. ${ }^{86}$

Second, this insufficient monitoring was coupled with low penalties. Hospitals found to have violated the regulations face only a $\$ 2000$ fine for the

79. Id.

80. Whetsell, supra note 47 , at 55 .

81. See Boodman, supra note 53; Ann Japenga, Endless Days and Sleepless Nights: Do Long Work Schedules Help or Hinder Medical Residents?, L.A. TIMES, Mar. 6, 1988 at 1.

82. John Ronches, Must We Squander the Legacy of Libby Zion?, NEWSDAY, Jan. 3, 1995, at A24.

83. Id.

84. Id.

85. Id.

86. Id. 
first violation. ${ }^{87}$ Given the very low risk of getting caught, and the very small penalty if one does get caught, it is not unexpected that hospitals would not place a high priority on compliance.

\section{b. Financing}

Although New York did not effectively enforce the regulations, this lack of enforcement alone does not explain why most New York hospitals chose not to comply. While enforcement of the regulations has been weak overall, there have been periods when New York did cite a large number of hospitals for violations. For instance, New York's Department of Health conducted a series of raids in March 1998, which uncovered numerous violations at several prestigious teaching hospitals, ${ }^{88}$ a similar raid took place in 2002 , uncovering even more violations. ${ }^{89}$

Rather than reacting to such raids by increasing compliance with the regulations, hospitals chose to take creative measures to avoid getting caught violating them. One hospital, for example, generated two separate schedules for residents - one for clinic duties and another for in-patient duties - that were not reconciled. ${ }^{90}$ Another hospital sought to circumvent the regulations by officially scheduling residents for twelve-hour shifts in compliance with the regulations but making it clear that they were actually required to arrive an hour or two before the official starting time and expected to stay after the official ending time. ${ }^{91}$ Even more hospitals would schedule "technically optional" conferences that would not be included in the official work schedule, but require residents to attend. ${ }^{92}$

Why would hospitals take such elaborate steps in order to avoid complying with the law? Hospitals have an obvious financial incentive not to comply with these regulations: If complying with the regulations would reduce a surgical resident's average work week from 130 hours to 80 hours, the hospital would have to hire other individuals to make up for the 50 hour deficit. The costs of hiring additional staff are substantial. Hiring just one additional physician

87. Susan Rubinowitz, Hosp Docs No Longer the Young and the Rest-less, N.Y. PosT, Jan. 26, 2000 , at 18 .

88. Lucette Lagnado, Raid of Hospitals Probes Overworked Doctors, Wall St. J., Mar. 11 , 1998 , at B1.

89. Margaret Ramirez, City Teaching Hospitals Brake Rules on Hours for Residents, NEWSDAY, June 27, 2002, at A49.

90. Esther B. Fein, Flouting Law, Hospitals Overwork Novice Doctors, N.Y. TIMES, Dec. 14, 1997 , at 1.

91. Id.

92. Id. 
assistant may cost a hospital anywhere from $\$ 67,000$ to $\$ 77,000$ per year, and an additional nurse practitioner's salary could range from $\$ 53,000$ to $\$ 98,000 .^{93}$ More skilled laborers, such as specialized physicians known as "hospitalists," have salaries ranging from $\$ 100,000$ to $\$ 150,000 .^{94}$ At some hospitals, the costs of hiring additional staff to compensate for lost resident labor can exceed $\$ 5$ million per year. ${ }^{95}$

One should note that the New York regulations were not a completely unfunded mandate: New York State gave hospitals. $\$ 55$ million a year to help comply with them. ${ }^{96}$ However, this money did not sufficiently cover the increased expense; the New York Department of Health estimated the initial cost of compliance at $\$ 227$ million, with continued compliance costing $\$ 3.1$ billion for the first ten years and $\$ 5.7$ billion over the first fifteen years. ${ }^{97}$ Not only was $\$ 55$ million a year insufficient, but hospitals had no guarantee that the state would perpetually provide them with. $\$ 55^{\circ}$ million a year. Furthermore, since hospitals were not required to account for how they spent the money, ${ }^{98}$ hospitals seeking to maximize their economic position could spend this money on other things and continue not to comply with the regulations, considering the low levels of enforcement and low penalties.

\section{c. Culture}

While financial incentives played a very large role in hospital noncompliance with the New York regulations, one cannot ignore the role of culture. As discussed earlier, doctors have historically believed that residents should work long hours for a variety of reasons, ranging from pedagogical ${ }^{99}$ to psychological. ${ }^{100}$ It should come as no surprise that a culture so entrenched would not change overnight.

Additional cultural factors, however, likely contributed to hospitals' unwillingness to comply. Hospitals have historically been given a significant amount of deference, and for the most part they have been allowed to set their

93. Debra F. Weinstein, Duty Hours for Resident Physicians - Tough Choices for Teaching Hospitals, 347 NEW ENG. J. MED. 1275, 1276 (2002).

94. Bruce Japsen, Residents Rules Cost Hospitals Millions, CHI. TriB., July 10, 2005, at C1.

95. Katherine Vogt, Hospitals Count Up Cost of Reduced Resident Hours, AM. MED. NEwS, Aug. 11, 2003, available at http://www.ama-assn.org/amednews/2003/08/11/bisc0811.htm.

96. Ronches, supra note 82 .

97. Gao, Health Care: Reduction in Resident Physician Work Hours Will Not Be EASY TO ATTAIN 4 (1992) [hereinafter GAO REPORT]:

98. See Ronches, supra note 82.

99. Pelton, supra note 52.

100. Groopman, supra note 55. 
own standards; thus, hospitals have generally been suspicious of government interference in their affairs. ${ }^{101}$ Since "regulations may be crafted by legislators who lack intimate knowledge of the health care system," hospitals are reluctant to blindly follow government mandates without solid evidence that such regulations are truly beneficial and necessary. ${ }^{102}$. Hospitals did not believe that the New York state government provided solid evidence. In fact, even today many hospitals and residency program directors argue that there is no relationship between work hour limits and patient safety. ${ }^{103}$ Doctors in other states oppose state work hour legislation for similar reasons and believed hospital administrators, and not the government, should make these decisions. ${ }^{104}$

\section{The Current State of Affairs: ACGME Regulation}

When state regulation of resident work hours failed to meet expectations, some believed that residency programs simply would not submit to any form of external regulation of resident working conditions. The early twenty-first century, however, has seen a significant change in how resident work hours are regulated. On June 11, 2002, the ACGME announced that, as of July 1, 2003, all accredited residency programs would have to comply with the ACGME's resident work hour regulations in order to keep their accreditation. ${ }^{105}$

While New York State resident work hour regulations stemmed from the Libby Zion incident, there was no single event that precipitated the ACGME's decision to regulate nationwide. Public outcry, in fact, played little, if any, role in the ACGME's decision. Instead, the ACGME was likely motivated by a series of events that, while receiving significantly less media attention than Libby Zion, posed a real threat to both hospital and ACGME control over residency programs.

101. Robert Trowbridge \& Robert M. Wachter, Legislation, Accreditation, and Market-Driven and Other Approaches to Improving Patient Safety in Making Health CARe Safer: A CritiCal Analysis of Patient Safety Practices 601, 602 (Amy J. Markowitz ed., 2001), available at http://www.ahrq.gov/clinic/ptsafety/pdf/ptsafety.pdf.

102. Id.

103. See infra Section III.C (discussing why many hospitals and residency program directors believe limiting resident work hours does not enhance patient safety).

104. See, e.g., David Abel, Bill Would Put Federal Limit on Residents' Marathon Hours, S.F. CHRON., Dec. 31, 2001, at J3 ("'I think legislation is a dangerous way to go when we are trying to provide the best training,' said Elizabeth Stengel, director of the Conference of Boston Teaching Hospitals. 'It doesn't allow flexibility and its just much better that doctors and hospital administrators make the decisions."').

105. Hall, supra note 51. 


\section{Resident Unionization}

Hospitals have historically been identified as organizations that "are most supportive of steep hierarchies in which junior staff do not question senior staff." 106 This hierarchical nature certainly applies to residencies, for the purpose of a residency program is for a resident to acquire training in a specialty area by supervising physicians who are already skilled specialists in their fields. ${ }^{107}$ However, a ruling by the National Labor Relations Board (NLRB) in 1999 had the potential to change fundamentally the relationship between residents and their superiors.

The controversy in Boston Medical Center Corp. ${ }^{108}$ began with the merger of Boston City Hospital, a public hospital, and Boston University Medical Center Hospital, a private hospital, to create the Boston Medical Center, a private entity. ${ }^{109}$ Due to Massachusetts's Public Employee Benefits Act, residents at Boston City Hospital had been unionized since 1969, while the Boston University Medical Center Hospital had not recognized a resident union. ${ }^{110}$ Although the Boston Medical Center was required to recognize Boston City Hospital's union as a condition of the merger, the residents' union, the Committee of Interns and Residents, brought the case before the NLRB in order to test whether residents at private institutions are primarily students or employees. ${ }^{111}$

The NLRB, in a split decision, reversed more than twenty years of precedent. ${ }^{112}$ The majority found that residents, "while they may be students learning their chosen medical craft, are also 'employees' within the meaning of Section 2(3) of the [National Labor Relations] Act." ${ }^{\text {"13 }}$ Under this decision, medical residents were given all the rights given to other workers protected under the NLRA, including the ability to bargain collectively and strike. ${ }^{114}$

The Boston Medical Center ruling drew immediate criticism from several prominent medical professional organizations, which saw the decision as a threat

106. Trowbridge \& Wachter, supra note 101.

107. PRIMER, supra note 35 , at 2.

108. 330 N.L.R.B. 152 (1999).

109. Id.

110. Id.

111. Am. Ass'n of Med. Colls., Resident Unionization, http://www.aamc.org/advocacy/ library/workforce/work0003.htm (last visited Oct. 17, 2006).

112. See, e.g., St. Clare's Hosp. \& Health Ctr., 229 N.L.R.B. 1000 (1977); Cedars-Sinai Med. Ctr., 223 N.L.R.B. 251 (1976) (holding that medical residents are primarily students, not employees).

113. 330 N.L.R.B. at 152.

114. Id. 
to medical education's traditional hierarchical structure. The Association of American Medical Colleges (AAMC) issued a statement condemning the decision, stating that the decision "has far-ranging, potentially damaging implications for the future of physician training in this country." 115 The AAMC's president, Jordan J. Cohen, went on to say that labor disputes and other issues arising out of medical education programs "should be the responsibility of the faculty and teaching institution," and that "residents should not have the right to strike and that the ability to do so, which is one of the primary entitlements associated with unions, is incompatible with the medical education process." 116 The ACGME, while not condemning the NLRB's decision outright, issued a statement affirming its ability to regulate resident working environments. In this statement, which was circulated to all residents, the ACGME emphasized that "[r]esidents are first and foremost students, rather than employees, and all accreditation standards and activities reflect this distinction.",117

\section{Federal Government Regulation}

Resident unionization was not the only potential threat to hospital and ACGME control over residency programs nationwide. Not long after the NLRB decided the Boston Medical Center case, some individuals within the U.S. government contemplated federal regulation of resident working conditions.

The early twenty-first century was not the first time the federal government considered the possibility of regulating resident work hours. In fact, the U.S. government first considered the possibility in 1991, three years after the New York State regulations were instituted. Illinois Congressman Marty Russo, contemplating federal resident work hour legislation, asked the Human Resources Division of the U.S. General Accounting Office (GAO) to investigate whether the "quality of care delivered by resident physicians could be improved" through federal legislation limiting resident work hours. ${ }^{118} \mathrm{GAO}$, after a yearlong study, concluded that residents who work long hours with minimal supervision "are likely to be more at risk of making errors than are properly rested and supervised personnel." 119 However, the GAO report found that federal legislation

115. Press Release, Am. Ass'n of Med. Colls., AAMC Statement on NLRB Boston Medical Center Ruling (Dec. 8, 1999), available at http://www.aamc.org/newsroom/pressrel/1999/ 991130.htm.

116. Id.

117. Memorandum from David C. Leach, Executive Director, ACGME, to Member Organizations of the ACGME (Mar. 1, 2000), available at http://www.acgme.org/acWebsite/ reviewComment/rev_residentEmployee.asp.

118. GAO REPORT, supra note 97 , at 1 .

119. Id. at 5 . 
may not succeed in resolving the problem, since many hospitals, particularly those in inner cities, would not limit work hours unless the costs of compliance were fully reimbursed. ${ }^{120}$ After receiving this report, Congressman Russo did not introduce a bill seeking to limit resident work hours.

For the next decade, the federal government made no significant attempt to regulate work hours. In April 2001, however, the Committee of Interns and Residents, an affiliate of the Service Employees International Union, ${ }^{121}$ joined by the American Medical Student Association and the Public Citizen Health Research Group, petitioned the Occupational Safety and Health Administration (OSHA) to "enforce a federal work hour standard for residents." 122 OSHA stated that it did not believe it had the purview to regulate resident work hours. ${ }^{123}$ Although this petition was unsuccessful, it got the attention of Michigan Congressman John Conyers, Jr., who introduced the Patient and Physician Safety and Protection Act, H.R. 3236, in November 2001. ${ }^{124}$ This bill would have limited residents to eighty hours of work per week and would not have permitted averaging of weeks. ${ }^{125}$

Shortly before H.R. 3236 was formally introduced, the AAMC, in an attempt to eliminate the need for federal legislation, changed its position on the resident work hour issue and recommended that "in no case should residents be scheduled to be on duty more than 80 hours a week." ${ }^{126}$ While this declaration was not binding on any residency program, the AAMC cited it as evidence that government intervention was not necessary. In a letter to Congressman Conyers, AAMC President Jordan J. Cohen wrote that the AAMC "agree[d] that the issues addressed in this legislation are very important" but felt that legislation was not appropriate, since "[t]he mechanisms that are in place in the private sector to safeguard the public's interest in these matters have evolved over decades" and "the academic medical community ... ha[d] already made substantial progress in dealing with current concerns about resident and patient well being." concluded the letter by arguing that "continued reliance on these proven

120. Id.

121. Comm. of Interns \& Residents, Who We Are, http://www.cirseiu.org/ourlocal/ (last visited Oct. 17, 2006).

122. Robert Steinbrook, The Debate Over Residents' Work Hours, 347 NEw ENG. J. MED. 1296, 1297 (2002).

123. Jay Greene, Petition Asks OSHA To Limit Resident Work Hours, AM. Med. News, May 21, 2001, http://www.ama-assn.org/amednews/2001/05/21/prsa0521.htm.

124. H.R. 3236, 107th Cong. (2001).

125. See Steinbrook, supra note 122, at 1296.

126. Id. at 1297.

127. Letter from Jordan J. Cohen, AAMC President, to John Conyers, Jr., U.S. Representative (Jan. 4, 2002), available at http://www.aamc.org/advocacy/library/educ/corres/2002/010402.htm. 
mechanisms offers a far greater likelihood of success in dealing with the concerns addressed by H.R. 3236 than does the introduction of legislative and regulatory strictures into the complex environment of graduate medical education." 128

When it became clear Congressman Conyers had no intention of withdrawing the bill, and that New Jersey Senator Jon Corzine also intended to introduce the bill in the Senate (as S. 2614), the ACGME decided to place formal limits on resident work hours at ACGME-accredited residency programs. ${ }^{129}$ On June 11, 2002, the day before Senator Corzine introduced S. 2614, the ACGME announced that, effective July 1, 2003, residents could be scheduled for no more than eighty duty hours per week, averaged over four weeks, with provisions allowing for increases in certain circumstances. ${ }^{130}$ Neither H.R. 3236 nor S. 2614 received a vote from their respective houses of Congress, and when Representative Conyers reintroduced his bill as H.R. 1228 the following year it also failed to receive a vote. ${ }^{131}$

\section{EVAlUATING EXISTING REgUlatory SCHEMES}

Academics and practitioners have generally identified three possible ways to regulate resident working hours and conditions: public decentralized regulation, public centralized regulation, and private centralized regulation. This Part discusses the costs and benefits of these regulatory systems relative to an unregulated market.

\section{A. No Regulation: The Free Market}

The laissez-faire period in graduate medical education was an era of a free market, in which residency programs themselves were able to determine resident working hours and conditions without external oversight. ${ }^{132}$ As discussed earlier, this free market system led to inefficient outcomes due to its inability to handle externalities, such as the medical mistakes that led to the deaths of Libby Zion

128. Id.

129. See Michael Romano, Hours of Doctors-in-Training: Who's Counting?, MoD. HealthCare, Aug. 19, 2002, at 18 (quoting Peter Lurie, deputy director of the Public Citizen advocacy group, who called the ACGME regulations "a last-gasp effort to save off federal legislation").

130. Steinbrook, supra note 122.

131. Am. Ass'n of Med. Colls, Washington Highlights: April 1, 2005, http://www.aamc.org/ advocacy/library/washhigh/2005/040105/start.htm (last visited Dec. 8, 2006) (see subheading Conyers Reintroduces Resident Hours Legislation).

132. See supra Section II.A (summarizing the laissez-faire period). 
and others. ${ }^{133}$ Though some residency program directors may prefer such a system and wish to return to such an era, such a change is unlikely to occur since other stakeholders in graduate medical education are no longer willing to potentially compromise patient safety. ${ }^{134}$

In recent years, however, some have proposed an alternate free market approach involving a shift in bargaining power. Rather than allowing individual residency programs to unilaterally determine working hour policies, residency programs would decide these policies together with residents themselves. ${ }^{135}$ There is little dispute that economics played at least some role in shaping working hour policies during the laissez-faire period: Since residents provided hospitals with a cheap source of labor, hospitals had an incentive to require their residents to perform ancillary tasks that were unrelated to the educational goals of a residency program. ${ }^{136}$ Residents lacked any semblance of bargaining power and could not prevent programs from assigning them to such tasks. ${ }^{137}$

The NLRB's 1999 decision in Boston Medical Center, ${ }^{138}$ granting medical residents at private institutions the right to unionize, could allow medical residents, through their unions, to negotiate working hours and conditions as part of a collective bargaining agreement. There are clear advantages to such a system. Since residents receive minimal benefit from "scut work" and greatly prefer tasks that further education in their specialty, it is likely that meaningful negotiation between programs and residents would result in a reduction of hours performing "scut work" without a reduction in hours spent on training. As a result, residents might work fewer hours and eliminate or lessen the externality, while simultaneously not compromising their educational training. Furthermore, hospitals and residents could implement work hour regulations that are individually tailored to specific programs within specific institutions.

Although this new spin on free market regulation seems like the ideal solution, in practice it is highly unlikely to result in any meaningful reforms. First, it is doubtful that a critical mass of medical residents will ever become unionized. Unlike steelworkers or teachers, no individuals are medical residents

133. See supra Section II.B (summarizing the shift from the laissez-faire system to state regulation).

134. See supra Sections II.B-C (explaining why the government and other stakeholders will no longer tolerate a lack of regulation).

135. See Jason van Steenburgh, Under Pressure, Medicine Revisits Resident Work Hours, ACPASIM OBSERVER, Mar. 2002, available at http://www.acponline.org/journals/news/mar02/ resident.htm (stating that some organizations have attempted to work with residents to negotiate working conditions directly with hospitals).

136. Ludmerer \& Johns, supra note 49, at 1084.

137. Id.

138. 330 N.L.R.B. 152 (1999). 
for their entire professional lives; all medical school students applying for resident positions know that their residencies are temporary positions that will only last for a certain number of years before they can move on to more lucrative opportunities of their own choosing. As a result, there is little incentive for medical residents to organize, particularly when the residents leading the organizing effort are unlikely to reap the benefits of unionization themselves, since the union recognition and collective bargaining process can take years. ${ }^{139}$

While some might argue that the temporary nature of teaching assistant positions has not prevented graduate students from pursuing unionization, the situations are not analogous. Medical resident salaries are virtually identical from program to program, and other points of contention, such as work hours, do not vary much among programs within a given specialty. ${ }^{140}$ Since medical residents at a given program or hospital are unlikely to believe they are worse off relative to their peers elsewhere, ${ }^{141}$ there is substantially less need for a union. The fact that only a small handful of medical residents have even attempted to unionize since the 1999 NLRB decision casts further doubt on this theory. ${ }^{142}$

Furthermore, the free market would be unlikely to create meaningful changes even if there were widespread demand among medical residents for unionization. The very high incidence of non-compliance with New York State's medical resident regulations as late as the 1990s shows that hospitals are not above ignoring laws if the benefits of non-compliance are significantly higher than the costs of compliance. Although American labor law provides certain protections to workers who are trying to organize, the procedure and remedies for enforcing these protections under the National Labor Relations Act (NLRA) are extremely weak. The process involves first filing a complaint with an NLRB office claiming the statute was violated, waiting for that office to investigate the allegation and issue a complaint, and then bringing a case before an

139. Guaranteeing Employee Free Choice Through Democratic "Card-Check" Procedures, http://www.wslc.org/photos/temp/EFCA-cardcheck.doc (last visited Dec. 9, 2006).

140. Primer, supra note 35, at 6,13; Neil A. Lewis, Medical Establishment Turns to Powerful Allies To Thwart Residents' Lawsuit, N.Y. TIMES, Aug. 18, 2003, at A10.

141. Studies show that an individual's psychological feelings toward issues such as pay will differ based on how other individuals he or she knows about are treated. For instance, studies have found that employees who work at organizations with two-tier wage structures, where new employees are paid less than current employees even though they perform the exact same work, are highly dissatisfied and significantly more likely to quit, since the wage differentials are viewed as very unfair. See Jerald Greenberg \& Robert A. Baron, Behavior in Organizations 147 (2000). Similarly, when individuals know that employees at other organizations are paid more money for the same work, they are also more likely to feel resentful and take action to end the perceived inequality. Id.

142. Am. Ass'n of Med. Colls., Resident Unionization, supra note 111. 
administrative law judge who may make non-binding recommendations. If the parties disagree, the matter is heard by the five members of the NLRB, which, while having the power to make an actual decision, does not have the power to compel either party to comply it. ${ }^{143}$ For an NLRB decision to have binding impact on the parties, it must be affirmed by a U.S. Circuit Court of Appeals. This is an extremely long process, and it is certainly not uncommon for many years, and in some cases even decades, to pass from the time the unfair labor practice took place to the time an appellate court renders a binding decision. ${ }^{144}$ Furthermore, even if the appellate court affirms a decision against the employer, the employee can only receive back pay (or reinstatement) as compensation and never punitive damages. ${ }^{145}$ Given that widespread medical resident unionization has the potential to cost hospitals millions, and given that few residents would have the resources or desire to commence litigation that has the potential to last longer than their entire residency program, it is highly unlikely that a meaningful number of medical resident unions would ever get certified even if most residents wanted to unionize. Barring radical changes in American labor law, free market regulation with resident union input is unlikely to happen.

It is also incorrect to assume that medical resident unions would properly handle the patient safety externality. Residents and patients do not share the same interests. A medical resident union, like other unions, would view furthering its own members' interests as its primary goal. In this case, furthering member interests would likely involve improving resident quality of life and enhancing the educational value of residency programs; if one believes these should be the primary goals of resident work hour regulation, resident unionization may be an acceptable solution. However, if increasing patient safety takes precedence over those other goals, the misalignment of patient and resident interests would make unionization an ineffective means of achieving this greater goal.

While some may argue that furthering some resident goals may also further the interests of patients, there is no guarantee that this would actually transpire. For example, rather than demanding fewer hours through the elimination of "scut work," a medical resident union might ask that total work hours remain the same, but conferences and other educational activities replace hours that were previously used to perform ancillary functions. Alternatively, residents might not ask for changes in working conditions at all, and just negotiate for large salary increases, so that residents are paid on par with physician assistants, nurse practitioners, and other hospital personnel who perform some of the same duties as residents.

143. See generally RoBERT J. RABIN et al., LABOR AND EMPLOYMENT LAW at ch.2 (3d ed. 2002).

144. Id.

145. Id. 
Although fewer hours will likely increase a resident's quality of life, residents may not want to work fewer hours. Residents enroll in residency programs in order to obtain training in a specialty; a decrease in total work hours, even if geared toward reducing "scut work" hours, could conceivably result in residents obtaining less training than under a system where work hours are not restricted. Residents may fear that residency programs might become extended to make up for this difference. ${ }^{146}$ Since residents must already go through four years of college and an additional four years of medical school as well as their relatively low-paying residency before they can obtain higher paying jobs, many residents may not accept a higher quality of life during residency if it means delaying entry into lucrative jobs by one or two more years.

Even if residents did successfully negotiate fewer hours, there is no guarantee that residents would use this extra time to get more sleep. One study, for instance, found that residents given "protected time," during which they were not on call, did not use their free time to sleep, but instead to engage in other activities. In fact, they averaged the same amount of sleep as residents who did not have the extra free time. ${ }^{147}$ Thus, while fewer hours may result in higher resident quality of life, they may not further the objective of patient safety if residents do not use their additional free time to get more rest.

\section{B. Public Decentralized Regulation}

New York State experimented with public decentralized regulation of residency programs starting in 1989, when it implemented the Bell Regulations. ${ }^{148}$ Originally, many individuals believed other states would join New York in passing their own resident work hour regulations. Those favoring state regulation argued that, as Justice Brandeis observed in his famous dissent in New State Ice Co. v. Liebmann, ${ }^{149}$ each individual state would "serve as a laboratory" and "try novel social and economic experiments without risk to the rest of the country." 150 Of course, this did not take place: Other states did not create their own version of the Bell Regulations, ${ }^{151}$ and New York itself did a

146. See, e.g., Croasdale, supra note 57 ("One [resident] is convinced that the [ACGME work hour] rules eventually will mean an extension in the length of training programs because studies show that the more procedures performed the better the doctor becomes at them.").

147. G.S. Richardson et al., Objective Assessment of Sleep and Alertness in Medical House Staff and the Impact of Protected Time for Sleep, 19 SLEEP 718 (1996).

148. Colburn, supra note 76.

149. 285 U.S. 262 (1932).

150. Id. at 311.

151. Boodman, supra note 53. 
very poor job enforcing them. ${ }^{152}$

One should not interpret the failure of public decentralized regulation as a sign that it is not possible to experiment with novel approaches to resident work hour regulation. While public decentralized regulation suffers from several key flaws, these problems are not due to decentralization. Rather, the problems that prevented the success of public decentralized regulation stem from the government's involvement in both implementing and enforcing the regulations.

State governments are made up of politicians; as much as we might wish for elected officials not to consider politics when setting legislative priorities, in reality, politicians simply cannot afford not to take political considerations into account when deciding what bills they should support. Many people consider health care in general as a high priority and demand that politicians improve both state and national health care services; however, some health care issues are considered significantly more important than others. While many voters care about issues such as affordable health insurance, few voters may even be aware that long resident work hours may compromise patient safety.

Although few voters consider resident work hour regulation a major issue, doctors and medical organizations have very strong opinions on the issue, and are willing to express their opinions. For example, California's attempt at regulating resident work hours was defeated due to opposition from the California Medical Association and the California Association of Hospitals and Health Systems. ${ }^{153}$ Given the strength of the medical profession's lobbying abilities, the traditional deference given to professional organizations, and the fact that voters generally do not see this as a high priority issue, it is not surprising that politicians have largely been unwilling to push for state regulation of resident work hours.

Some would argue that this problem is not insurmountable; for instance, resident work hour regulations were implemented in New York State. However, one must examine what caused New York to implement these regulations. Clearly, media coverage of the Libby Zion incident increased public awareness of the resident fatigue problem ${ }^{154}$ and caused the public to demand action. But what is it about the Libby Zion incident that attracted so much media attention? Libby Zion was not the first New Yorker to die due to a mistake made by a medical resident, nor was she the last. Although Libby, as an eighteen-year-old college freshman, appears a sympathetic victim, other sympathetic individuals have died under similar circumstances in other states. For instance, Taylor McCormack, a thirteen-month-old baby, died in 2000 when residents at Boston's

152. Ronches, supra note 82.

153. Japenga, supra note 81 .

154. In this Note, the terms "resident fatigue problem" and "sleepy resident problem" are used interchangeably. 
Children's Hospital mistakenly placed her in a non-intensive-care room and postponed her surgery; ${ }^{155}$ the year before, William Katcher, a twenty-two-weekold baby, almost died at the same hospital due to residents failing to provide a breathing tube. ${ }^{156}$

Despite these shocking incidents, there was no public outcry for Massachusetts to implement resident work hour limits as there had been in New York after Libby Zion's death. ${ }^{157}$ One needs to consider the differences between these victims. Libby Zion's father, Sidney Zion, was a well-connected lawyer and journalist. ${ }^{158}$ Through his connections, Sidney Zion was able to draw substantial media attention to his daughter's death that otherwise would not have existed. In contrast, the families of William Katcher and Taylor McCormack were not as well connected, and therefore they did not receive the extensive media coverage or the criminal investigations that might have generated the public outcry necessary to push a bill through the Massachusetts legislature. One must acknowledge, therefore, that the New York situation was truly unique, and that it is not likely that similar situations will manifest themselves in a significant number of other states.

However, even Sidney Zion was not able to keep resident fatigue and patient safety in the headlines forever. Just as politicians do not possess an unlimited amount of political capital, government agencies do not possess unlimited budgets, and they must make trade-offs when deciding how to spend their money. As Libby Zion faded away and resident work hours moved out of the public's consciousness, New York's Department of Health, facing substantial budget cuts, no longer viewed enforcement of its resident work hour regulations as a high priority, ${ }^{159}$ and, with the exception of New York City Public Advocate Mark Green, elected officials saw no need to remedy the situation. ${ }^{160}$

Furthermore, government officials do not possess the same expertise and knowledge of the health care industry as do doctors and other medical professionals. Elected officials, even if well intentioned, are at a higher risk of

155. Anne Barnard, Teaching Hospitals' Dilemma: Instruction vs. Care for Harried Residents, Duties Not Clear-Cut, Boston GloBe, Aug. 10, 2001, at B1.

156. Id.

157. Although these incidents received some media coverage, it paled in comparison to coverage of Libby Zion's death, and this limited amount of media attention did not lead to state regulation of resident work hours in Massachusetts. Abel, supra note 104.

158. Horowitz, supra note 66.

159. See supra Sub-section II.B.2 (discussing New York's inability to enforce its regulations).

160. See Horowitz, supra note 66 ("However, in 1997, then-public advocate Mark Green released a report that exposed the defiance on the part of the hospitals and embarrassed the state Health Department. Since then, the state has cracked down with serious financial penalties for hospitals that don't comply."). 
instituting regulations that do little or nothing to solve the underlying problem than educated professionals who have a better understanding of the industry and its operations. ${ }^{161}$

\section{Private Centralized Regulation}

Private centralized regulation involves regulation by a non-governmental entity whose regulations have a national reach. Since July 2003, resident work hours have been regulated by the ACGME, a private centralized regulating entity. Unlike New York State, the ACGME has not had difficulty enforcing its regulations. As a private organization whose sole purpose is to evaluate and accredit residency programs, the ACGME has not had to make tradeoffs between enforcing its work hour regulations and other functions. Unlike a state Department of Health or other governmental entity, the ACGME's functions are highly interrelated and enforcing work hour regulations would not take a significant amount of time or money away from its other duties; ${ }^{162}$ thus, entrusting the ACGME with resident work hour regulation duties would naturally result in more efficient outcomes. ${ }^{163}$

\section{Implementation and Enforcement}

The ACGME work hour regulations met with significant skepticism. ${ }^{164}$ As a private organization, the ACGME lacks many of the attributes of government entities. Most notably, the ACGME does not have access to taxpayer money. Although New York State's $\$ 55$ million a year subsidy could cover only a fraction of the costs of compliance with its work hour regulations, the ACGME

161. Of course, this does not mean that private organizations are not also at risk of instituting bad regulations. See supra Section II.C (discussing the problems with the ACGME work hour regulations).

162. There are many parallels between the ACGME's primary role of assessing the quality of residency programs and its secondary role of enforcing work hour regulations. For example, since the ACGME already routinely conducts more than 1900 site visits every year to ensure compliance with its other regulations, it should pose no hardship for the ACGME to measure compliance to its work hour regulations during these visits. See Accreditation Council for Graduate Med. Educ., The Role of the ACGME, http://www.acgme.org/acWebsite/about/ab_roleACGME.asp (last visited Dec. 9, 2006) (discussing the role of the ACGME).

163. Of course, if state governments took over the ACGME's accreditation function in addition to regulating work hours, they could also benefit from this; however, all the other problems of public decentralized regulation discussed earlier would still apply.

164. See, e.g., Hall, supra note 51 ("Out on the hospital floor, however, many physicians in training said they doubt much will change, citing a hoary tradition of absurd hours for novice doctors as well as their own shockingly low salaries."). 
regulations were a true unfunded mandate. Even if it wanted to, the ACGME could not cover the full costs of hospital compliance with its regulations. Therefore, some speculated that hospitals would ignore the ACGME regulations much as they did the New York regulations. ${ }^{165}$

While some residency programs did initially fail to comply with the ACGME regulations, the overwhelming majority of programs did comply, even without funding to make up the differentials. ${ }^{166}$ Unlike New York State, the ACGME was able to make the potential costs of non-compliance significantly greater than the benefits: The ACGME stated that failure to comply with the ACGME work hour regulations could result in the ACGME withdrawing or temporarily suspending a residency program's accreditation. ${ }^{167}$

The loss of ACGME accreditation has far greater consequences than a $\$ 2000$ fine. If a residency program loses ACGME accreditation, its graduates are not eligible to take the examinations required to become certified in their specialty. ${ }^{168}$ In addition, many federal government subsidies of residency programs are directly tied to ACGME accreditation. For example, programs that do not have ACGME accreditation are not eligible for Medicare funds that are earmarked for support of graduate medical education ${ }^{169}$ Such subsidies are substantial: In 1998, Medicare contributed almost $\$ 6.7$ billion to teaching hospitals to help with the growing costs of training physicians. ${ }^{170}$ Thus, while hospitals might find it burdensome to spend up to $\$ 5$ million a year to comply with the ACGME's work hour restrictions, the costs of compliance are significantly lower than the costs of non-compliance, which gives hospitals a very strong incentive to comply. ${ }^{171}$

Furthermore, the ACGME made it clear very early in the process that the loss of accreditation was not an idle threat. The ACGME, after receiving a report in 2002 that Yale-New Haven Hospital's general surgery residency program was

165. See, e.g., Romano, supra note 129 (stating that the ACGME regulations are "inadequate" and do not force public disclosure for violations).

166. Tracking Residency Work-Hour Violations, Am. Med. News, Dec. 5, 2005, available at www.ama-assn.org/amednews/2005/12/05/prca1205.htm [hereinafter Violations].

167. Accreditation Council for Graduate Med. Educ., ACGME Duty Hours Standards Fact Sheet, http://www.acgme.org/acWebsite/newsRoom/ACGMEdutyHoursfactsheet.pdf (last visited Oct. 17, 2006).

168. Id.

169. Id.

170. Primer, supra note 35 , at $14-15$.

171. Dr. David Leach, Executive Director of the ACGME, has stated that "[d]uty hours are being met" because " $[t]$ he financial incentives are too heavy to risk having your accreditation withdrawn." Myrle Croasdale, Resident Work-Hour Limits Still a Struggle One Year into Restrictions, AM. MED. NEws, July 19, 2004, available at http://www.ama-assn.org/amednews/ 2004/07/19/prl10719.htm. 
requiring its residents to work more than 100 hours per week, immediately stated that it would withdraw the program's accreditation if it did not comply with new ACGME requirements by July $2003 .{ }^{172}$ One week after the work hour requirements went into effect, the ACGME stated that it intended to withdraw accreditation of Johns Hopkins Hospital's internal medicine program, effective July 2004, due to violations. ${ }^{173}$

The ACGME, unlike New York, has also shown no signs of reducing enforcement. During the 2004-05 academic year, the ACGME reviewed 2002 of the 8037 ACGME-accredited residency programs for violations. ${ }^{174}$ Of these programs, it cited only 147 for duty-hour violations. In other words, $92.7 \%$ surveyed programs were in compliance with the ACGME regulations. ${ }^{175}$

\section{Problems with Private Centralized Regulation}

At first glance, one may think that ACGME regulation has been highly successful. After all, in just two years the ACGME has managed to get more than ninety-two percent of residency programs to comply with its work hour regulations, without the need for legislation or substantial government aid. ${ }^{176}$ However, a closer examination of ACGME regulation shows several disadvantages to entrusting the ACGME with this responsibility.

Perhaps the most serious problem with the ACGME as a regulator is that it has imposed a one-size-fits-all set of regulations on all residency programs without determining whether its regulations can further the underlying goal of improving patient safety. The ACGME, by forcing residency programs nationwide to implement the ACGME regulations, has made individual residency programs unable to experiment with alternate methods of improving patient safety. Of course, the inability of residency programs to experiment with alternate methods would not be considered a major loss if there were a universal consensus that the ACGME's regulations were the best solution to the sleepy resident problem. However, such a consensus does not exist; in fact, a substantial portion of the medical community believes that the ACGME regulations may actually work against the goal of improving patient safety.

Some hospitals have responded to the ACGME work hour limits by creating

172. Adam Mehes, Med School Program Reaccredited, Yale Dally News, Oct. 30, 2002, available at $\mathrm{http}: / / \mathrm{www}$.yaledailynews.com/article.asp?AID $=20458$.

173. Patrick Gilbert \& Mary Ellen Miller, Out of Time, HOPKINS MED., Winter 2004, available at http://www.hopkinsmedicine.org/hmn/W04/top.cfm.

174. Violations, supra note 166.

175. Id.

176. See Violations, supra note 166 (discussing the relatively low rate of non-compliance with the ACGME regulations). 
two shifts - a day shift and a night shift - and hiring additional physicians to make up the difference. Brigham and Women's Hospital in Boston, for instance, responded to the change by hiring an additional thirty doctors to cover the night shift. ${ }^{177}$ Many doctors, however, argue that having different doctors cover different shifts will endanger patient safety by impairing continuity of care. The chief surgeon of Massachusetts General Hospital stated that having different teams is a bad idea because night shift doctors would not be as familiar with patients admitted in the day shift, and vice versa. ${ }^{178}$ Such lack of familiarity may lead to doctors making poor decisions; the chair of Boston Medical Center's orthopedic surgery department also observed several "poor patient care decisions and outcomes resulting from the on-call doctor not giving a good handoff, which is a symptom of the 80-hour rule." 179 Another doctor found significant continuity of care problems at her hospital. In fact, she and other attending physicians have had to devote a substantial amount of additional time reviewing $\mathrm{x}$-ray findings, intake and output records, and other patient information because residents are rarely able to complete these important tasks when forced to sign out. ${ }^{180}$ Despite attempts to mitigate the problem, this doctor has still observed a significant decline in patient safety at her hospital. After all, "[h]ow can a housestaff team be expected to determine whether cellulitis is improving or worsening if the same individual does not examine the patient on consecutive days?"'181

Such concerns from physicians are not uncommon. In fact, a national survey of neurosurgery programs conducted by the Mayo Clinic found that ninety-three percent of residency program directors and residents themselves felt that the ACGME's work hour limits hurt continuity of patient care. ${ }^{182}$ A survey of ob-gyn residents conducted after the regulations went into effect found similar results. Most ob-gyn residents viewed the hour limits as problematic due to loss of continuity, and some were concerned that they would miss the deliveries of patients they were following due to the eighty-hour limit. ${ }^{183}$

177. Anne Barnard \& Liz Kowalczyk, Medical Resident Workload Curbed Big Impact Seen on Hub Hospitals, Boston GloBe, June 13, 2002, at Al.

178. Id.

179. Croasdale, supra note 57.

180. Amy L. Friedman, Letter to the Editor: Resident Work Hour Limits Are Compromising Patient Safety, AM. MED. News, Aug. 4, 2003, available at http://www.ama-assn.org/amednews/ 2003/12t03.htm (follow "Resident Work Hour Limits Are Compromising Patient Safety" hyperlink) (password protected).

181. Id.

182. Myrle Croasdale, The 80-Hour Experience: What Happens When Residents Have To Leave, AM. MED. NEWS, July 25, 2005, available at http://www.ama-assn.org/amednews/ 2005/07/25/prsa0725.htm.

183. Myrle Croasdale, Medical Residents Give Thumbs-Up to 80-Hour Limit, AM. MED. NEwS, 
Poor care decisions due to lack of continuity, however, are not the only patient safety concern associated with the ACGME regulations. While the ACGME limits have reduced the number of hours worked by medical residents, these limits have caused attending physicians to work longer hours to make up part of the difference. As one doctor put it, "[t]he work has to be done, and it's falling on the older physicians." 184 This same doctor observes that it is now not uncommon for her to be on call for up to forty hours at a time. ${ }^{185}$ In addition to spending more hours on call, attending physicians have to spend more time in educational conferences with residents, but as a result of the ACGME limits, it is not uncommon for some residents not to attend conferences about particular patients, since attending the conference would violate the ACGME regulations. ${ }^{186}$ Furthermore, in order to minimize the risks to patient safety due to lack of continuity of care, some attending physicians must spend hours collecting, rather than just reviewing, patient records, since residents rarely perform these functions before turning over patients to another shift. ${ }^{187}$ In fact, the work hour limits have caused the morning rounds of some attending physicians to last thirty to fifty percent longer than in the past, forcing these physicians either to work significantly longer hours or to see fewer patients. ${ }^{188}$ If fatigue and sleep loss increase the chance of medical errors, reducing resident fatigue while increasing attending physician fatigue may not improve patient safety.

However, there remains considerable doubt within the medical community as to whether limits on resident work hours actually reduce resident fatigue. The belief that work hour limits will translate into better rested residents relies on the assumption that residents, when given additional free time, will use that free time to sleep. ${ }^{189}$ Although the ACGME has taken this assumption for granted, studies have shown that this assumption is not as safe as one might think. One study, for example, found that decreasing work hours for one group of residents did not cause that group to sleep longer hours than another group of residents who continued to work the same schedule. ${ }^{190}$ An additional study found that surgical

Sept. 12, 2005, available at http://www.ama-assn.org/amednews/2005/09/12/prsb0912.htm.

184. Myrle Croasdale, Resident Hour Limits May Hit Attendings, AM. MED. NEws, July 7, 2003, available at http://www.ama-assn.org/amednews/2003/07/07/prsf0707.htm (quoting neonatologist Dr. Rajam Ramamurthy).

185. Id.

186. Id.

187. Friedman, supra note 180.

188. Id.

189. See, e.g., Am. Med. Student Ass'n, Principles Regarding Resident and Student Work Hours, http://www.amsa.org/about/ppp/rwh.cfm (last visited Oct. 17, 2006) (making a connection between fewer working hours and reduced fatigue and sleepiness).

190. Richardson, supra note 147. 
residents averaged the same amount of sleep per week regardless of whether they were on an every-other-night, every-third-night, or every-fourth-night on call schedule. $^{191}$ In fact, no study has found that work reductions cause sleep increases in residents. ${ }^{192}$

Other studies examining the indirect relationship between hours worked and patient care have not found a positive relationship between the two. For example, a 1991 study found that while work hour restrictions improved resident perceptions of their quality of life, there was no improvement in perceived patient care or resident examination scores. ${ }^{193}$ In fact, two studies - one conducted in $1998^{194}$ and the other in $2002^{195}$ - found that work hour reductions resulted in a perceived decrease in the quality of patient care, even though resident quality of life increased. Another study, which examined objective changes in patient care quality rather than perceived changes, found that work hour restrictions resulted in a greater number of complications and delayed test orderings by residents. ${ }^{196}$

Some may wonder why the ACGME implemented work hour regulations despite the lack of a consensus that work hour limits actually improve the quality of patient care. As discussed earlier, the threat of federal legislation played a major role in the ACGME's decision to tie work hour limits to program accreditation; rather than cede regulatory power to the federal government, the ACGME instituted its own regulations in order to lessen the need for governmental intervention and preserve its power. ${ }^{197}$ Given these circumstances, it is not surprising that, despite some differences, the ACGME regulations largely paralleled the proposed federal legislation. ${ }^{198}$

What is cause for concern, however, is the ACGME's inflexibility toward its regulations even after it became fairly certain that the government would not pass federal resident work hour legislation. The ACGME has not publicly announced that it will reexamine the efficacy of its regulations. In an article discussing the

191. R.G. Sawyer et al., Intern Call Schedules and Their Relationship to Sleep, Operating Room Participation, Stress, and Satisfaction, 126 SURGERY 337 (1999).

192. Sigrid Veasey et al., Sleep Loss and Fatigue in Residency Training, 288 JAMA 1116, 1122 (2002).

193. Kelly, supra note 24.

194. Conigliaro, supra note 23.

195. C.B. Barden et al., Effects of Limited Work Hours on Surgical Training, 195 J. AM. C. SURGEONS 531 (2002).

196. Laine Christine et al., The Impact of a Regulation Restricting Medical House Staff Working Hours on the Quality of Patient Care, 269 JAMA 374 (1993).

197. See supra Sub-section II.C.2 (discussing why the ACGME decided to implement its regulations).

198. Id. 
state of graduate medical education, Kenneth Ludmerer and Michael Johns expressed their displeasure with the ACGME's handling of its work hour regulations: " $[W]$ e find it disturbing that, without good evidence or outcome data, major regulations have been implemented that are contrary to the best judgment of many educators." 199

Several program directors feel that such inflexibility and overall lack of concern for educator input signifies an inherent problem with the ACGME. One such director believes that "[t]he ACGME has no idea what life as a patient or resident is like today, and I am frightened by what we are now turning out."200 While the ACGME has spent years evaluating the quality of residency programs, some feel that the ACGME has done a poor job evaluating its own performance, with the rapid implementation of its work hour limits and its unwillingness to consider other possibilities the result of a larger problem of poor internal self evaluation and little accountability to other organizations. ${ }^{201}$ Though some have recommended that the ACGME conduct a thorough internal review and submit to a peer review by an external commission, the ACGME has not taken such steps. ${ }^{202}$ Since the ACGME possesses a monopoly over graduate medical education accreditation, it has little or no incentive to improve itself, and individual residency programs have no choice but to submit to whatever policies the ACGME wishes to impose on them.

\section{Public Centralized Regulation}

Because the U.S. government has never instituted public centralized regulation of resident working conditions, it is not possible to point to examples of real world successes or failures. ${ }^{203}$ However, one can engage in informed speculation about the results of public centralized regulation by examining the pros and cons of public control as well as centralized control, drawing from experiences with both state regulation and ACGME regulation.

As with centralized ACGME regulation, federal legislation would impose a single standard on all residency programs, and thus prevent any experimentation. ${ }^{204}$ However, like public entities such as state governments, the federal government consists of politicians who must make tradeoffs among

199. Ludmerer \& Johns, supra note 49 , at 1086.

200. $I d$.

201. Id.

202. Id.

203. Although several European countries have passed national legislation limiting resident work hours, the inherent differences between graduate medical education in Europe and in the United States makes comparisons between the two difficult.

204. See supra Section III.B (discussing the benefits of experimentation). 
differing political priorities, as well as administrative and regulatory agencies that have multiple mandates and limited budgets. ${ }^{205}$ It is likely, then, that federal intervention would involve the government creating mandatory work hour limits over the objections of educators, but then not properly enforcing those limits due to a lack of political will or financial resources, as in New York; however, the legislation's national reach would have a chilling effect and prevent experimentation with other regulatory systems. Furthermore, the nature of the national political process would make amending poorly conceived regulations a longer and more difficult process. Therefore, it seems likely that public centralized regulation would bring about a "worst of both worlds" scenario. While society would suffer all the disadvantages of ACGME regulation and state government regulation, it would reap the benefits of neither.

This does not mean that the federal government has no role to play in graduate medical education. The federal government has greatly improved the quality of graduate medical education by providing billions of dollars in subsidies to teaching hospitals. ${ }^{206}$ Furthermore, the federal government may still pass legislation that enhances the strength of regulations implemented by other regulating bodies. For instance, many have believed that both the New York State regulations and the ACGME regulations lack adequate whistleblower protections for those who report violations. ${ }^{207}$ If such protections are non-existent or inadequate, the federal government would likely not cause substantial harm by extending federal whistleblower protection legislation to medical residents. Similarly, the federal government may require accreditors to publicly disclose the names of hospitals that have violated the accreditor's work hour regulations. ${ }^{208}$

205. See supra Section II.B (discussing the disadvantages of entrusting governments and government agencies with regulatory responsibilities).

206. PRIMER, supra note 35 , at 14-16.

207. The American Medical Student Association believes that the lack of whistleblower protection for residents who report suspected violations of the ACGME regulations may prevent many residents from coming forward, out of a fear that their superiors would retaliate against them by singling them out and providing poor letters of recommendation. Press Release, Am. Med. Student Ass'n, Medical Students Mark Historic Work Hours Reform with Call for Whistleblower Protection, Public Accountability (June 30, 2003), available at http://www.amsa.org/news/ release $2 . \mathrm{cfm}$ ?id=146.

208. Currently the ACGME is not required to publicly disclose the identities of hospitals that have violated its resident work hour guidelines. The American Medical Student Association believes that federal legislation is necessary to force the ACGME to make these disclosures. Am. Med. Student Ass'n, Frequently Asked Questions About Resident Work Hour Reform, http://www.amsa.org/rwh/faq.efm (last visited Oct. 17, 2006). 


\section{The Case for PRivate DeCEnTRalized Regulation}

Neither the free market approach nor any of the three regulatory schemes most frequently discussed by researchers seem ideal; while most possess at least one benefit over the others, all have at least one prominent cost that the others do not share. The free market, while allowing for experimentation, fails to internalize the externality of patient safety. While private centralized regulation internalizes this, it fails to allow for experimentation. State government regulation, while also allowing for experimentation, results in significant resource and enforcement problems that have little impact on patient safety. Lastly, federal government regulation would both prohibit experimentation and have no positive impact on patient safety, thus resulting in a significant cost without a corresponding benefit.

Given that a regulatory method should be adopted even if it is not ideal, most academics and practitioners who have taken a position on this issue have advocated for a particular regulatory method not because it will solve the underlying problems, but because other regulatory methods are comparatively weaker. ${ }^{209}$ This least-of-three-evils approach is appropriate if one considers only three choices that are known to be imperfect. However, there is no reason to limit this debate to only three regulatory choices. This Section argues that a fourth regulatory scheme exists that possesses the major benefits of the other schemes without suffering from their disadvantages: private decentralized regulation.

\section{A. What is Private Decentralized Regulation?}

Private decentralized regulation combines the private sector oversight found in private centralized (ACGME) regulation with the diversity of regulating bodies found in public decentralized (state government) regulation. Rather than permitting the ACGME monopoly over graduate medical education accreditation to continue, the U.S. government would disperse accreditation responsibilities to five or six separate private organizations operated by medical professionals. Each accreditor would maintain a monopoly over accrediting residency programs in a particular geographic region; in other words, residency programs would not have the option of "accreditor shopping." 


\section{B. Evaluating Private Decentralized Regulation}

\section{The Benefits of Private Decentralized Regulation}

Private decentralized regulation would ideally combine the benefits of public decentralized regulation with the benefits of private centralized regulation without incurring the costs of either system. Each new accreditor, like the ACGME, would remain a private entity whose primary purpose would involve evaluating the educational quality of residency programs. These accreditors would enforce their resident regulations just as the ACGME has been able to successfully enforce its regulations without much difficulty. ${ }^{210}$ Since site visits are already a part of an accreditor's responsibilities, these new accreditors would regularly visit hospitals and investigate violations just as the ACGME has been able to for the past two years. Because these accreditors serve narrow purposes and are privately funded, there is no danger that these organizations would cease enforcement because of budget cuts or a change in the political climate.

However, because accreditors would possess regional monopolies, rather than national monopolies, innovation and experimentation would take place. As discussed earlier, the medical profession has not yet reached a consensus on the resident work hour issue, with as many as ninety-three percent of neurosurgery residency program directors and residents believing that the current ACGME guidelines hurt continuity of care. ${ }^{211}$ Furthermore, those who find fault with the ACGME guidelines are unsatisfied with the regulations for different reasons, and they disagree as to the optimal solution to the sleepy resident problem. ${ }^{212}$ Given the extent of diversity of opinion on the issue, it is likely that medical professionals serving on the boards of five or six different graduate medical education accreditors would devise five or six different regulatory schemes. For example, one accreditor may institute a blanket eighty-hour work limit, a la the ACGME; another accreditor might not institute hour limits at all, but mandate that residents obtain a certain amount of rest before performing certain tasks, or require residents to sleep a certain number of total hours per week; still another accreditor may use a combination of work limits and mandated sleep, while yet another might acknowledge differences between specialties and have separate requirements based on specialty.

Through such experimentation, at least one regulatory system should present itself as clearly superior to the others. Once empirical evidence reveals a superior system, other accreditors will alter their regulations in order to adopt it. Doctors

210. Violations, supra note 166.

211. Croasdale, supra note 182.

212. See supra Section III.C (discussing the faults with private centralized regulation). 
and hospital administrators value empirical evidence. ${ }^{213}$ Although culture accounts for part of the opposition to work hour limits, ${ }^{214}$ most residency program directors have opposed the ACGME work hour limits due to the lack of evidence demonstrating a causal connection between lower work hours and higher patient safety. ${ }^{215}$ If empirical evidence were to show a strong relationship between fewer medical errors and a certain method of regulating resident work conditions - whether it be limiting hours, or mandating certain rest periods, or some other practice - program directors would likely support the change. ${ }^{216}$ However, attitudes will not change without evidence, ${ }^{217}$ and evidence will not manifest itself without experimentation. As long as the ACGME subjects residency programs nationwide to the same regulations, such experimentation will not take place, and neither the ACGME, program directors, nor society will know whether the current regulatory system is truly the best way to further the goal of patient safety.

\section{The Costs of Private Decentralized Regulation}

Some might argue that private decentralized regulation may raise concerns about equity. By subjecting residents in different geographic regions to different working conditions, with the knowledge that some working conditions are likely more conducive to patient safety than others, patients in some geographic areas may face a greater risk of being harmed by a resident's medical error than patients in other regions. This is certainly a possibility; however, one must remember that such tradeoffs always exist when making policy changes. Currently, very little evidence exists that there is a relationship between hours worked and patient safety. Not only has no study shown that residents will use their additional free time to sleep, but multiple studies have also demonstrated that work hour limits actually put patients in more danger due to impaired continuity of care and other factors. ${ }^{218}$

While some may find it psychologically pleasing to know that there are uniform national standards in place, the existence of such standards does not mean that the standards are ideal, nor does it mean that abandoning the standards would cause more harm either in the short term or the long term. If further experimentation through private decentralized regulation were to show that

213. Trowbridge \& Wachter, supra note 101.

214. See Groopman, supra note 55; Pelton, supra note 52.

215. Ludmerer \& Johns, supra note 49 , at 1086.

216. $I d$.

217. Trowbridge \& Wachter, supra note 101.

218. See supra Sub-section III.C.2 (explaining why some physicians oppose the ACGME regulations) 
limiting residents to eighty hours of work per week is the ideal regulatory system, then yes, the shift to private decentralized regulation would have caused a net harm, for some people in the country would have experienced increased harm while others would have retained their current safety levels. However, if experimentation proved that an eighty-hour work limit not only is not the best solution, but also that it is actually harmful to patient care, then the switch to private decentralized regulation would have made many people better off while making no one worse off than they were under the ACGME regulations; furthermore, by discovering that the eighty-hour limit is not the best way to further the goal of patient safety, all future patients would become better off as the accreditors who had retained the eighty-hour limit regulations in their regions would change their systems. Without actually knowing the most effective way to enhance patient safety, it is not possible to measure whether switching to private decentralized regulation would incur a net cost or net benefit to society. However, given the lack of evidence showing a connection between fewer work hours and improved patient safety, it seems more likely than not that a switch to private decentralized regulation would result in a net benefit rather than a net loss.

\section{Criticisms and Potential Barriers to Implementation}

For a variety of reasons, some may feel that private decentralized regulation is either harmful or impractical. This Sub-section will respond to these potential criticisms.

\section{a. Reversion to the Laissez-Faire System}

One might argue that residency programs have already had decades to experiment with different systems, but chose not to, suggesting that residency program directors may not truly desire innovation. Some might believe that these directors would try to persuade the new accreditors not to enact regulations at all, and they might demand a return to the laissez-faire system, just as medical organizations have lobbied against state and federal work hour legislation. ${ }^{219}$ Such beliefs are misguided.

While it is true that individual residency programs did not experiment with limiting resident work hours or other potential solutions to the sleepy resident problem during the laissez-faire period, one must acknowledge a fundamental difference between the role of a residency program director or hospital administrator determining policies for his or her own program or hospital and the

219. See supra Section III.B (explaining how medical lobbying organizations prevented California from enacting state regulations governing medical resident work hours). 
same individual serving as a member of an accrediting board. Hospitals exist in a competitive environment: A single hospital or residency program has very little incentive to unilaterally deviate from the status quo when doing so would incur considerable expense and little, if any, benefit. For example, if it would cost a hospital $\$ 2$ million a year to reduce the resident work week from 130 hours to 80 hours, a rational hospital administrator would not incur the expense unless enacting this change would cause the hospital to gain at least $\$ 2$ million a year in other benefits, such as having to settle fewer malpractice claims due to fewer patient errors. Even if a third party, such as society as a whole, would gain benefits exceeding \$2 million a year from the policy change, the hospital itself has no incentive to put itself in a worse position in order to benefit society. By implementing a policy change where the costs are greater than the benefits, the hospital would put itself in a worse position relative to its peer hospitals, who, as rational actors, would not have adopted such policies.

The same individual, however, in his or her capacity as a member of a regulatory board, would likely act differently. While an individual hospital has little or no incentive to unilaterally put itself in a worse position to benefit society, all hospitals in a given region have a greater incentive to engage in such action. If an individual hospital acts unilaterally, it loses its competitive position relative to other hospitals by incurring an expense that the others do not also bear; however, this concern disappears if all hospitals in a given region make the same change and incur similar expenses.

Although medical professional organizations have lobbied against state and federal regulations, one must remember that medical professional opposition was rooted in resistance to government regulation and not a sentiment against regulation in general. ${ }^{220}$ Physicians, as discussed earlier, are deeply suspicious of government intervention, particularly when there is a lack of evidence that such intervention is even necessary, and they prefer that health care professionals create regulations. ${ }^{221}$ Although physicians also generally oppose the ACGME regulations, this opposition is due to the ACGME's decision to implement major regulations nationwide, without evidence that the regulations have any efficacy and against the advice of educators and informed medical professionals, which is a reflection of the ACGME's growing detachment from practitioners. ${ }^{222}$ If the new regional accreditors pledged to obtain a significant amount of input from residency program directors and other medical educators before deciding on a set of regulations, it is doubtful that the medical community would lobby against

220. See supra Sub-sections III.B-C.1 (discussing why doctors opposed attempts at state and federal regulation of resident work hours).

221. Id.

222. Ludmerer \& Johns, supra note 49 , at 1086. 
private decentralized regulation.

Furthermore, one must consider the political environment that gave rise to the ACGME regulations. As discussed earlier, the ACGME did not truly desire to regulate medical resident working hours; rather, the emerging threats of resident unionization and federal government regulation forced the ACGME to institute regulations in order to allow the health care profession to retain some semblance of control over resident working conditions. ${ }^{223}$ This threat of external control would remain if a shift to private decentralized regulation occurred. The medical professionals serving on accrediting boards, even if they personally would rather see a return to the laissez-faire system, would understand that such a decision might motivate the federal government to pass federal work-hour legislation over the objections of those in the medical profession. Since the medical profession has demonstrated that it wishes to retain at least some control over resident work hours, ${ }^{224}$ it is unlikely that any accreditor would refuse to regulate resident working conditions, for such a move would likely cause the federal government to take the choice out of their hands permanently.

\section{b. Impact of Resident Preferences}

Although residency programs would not be able to pick their accreditor under a private decentralized regulation system, residency program applicants would have the ability to select their residency programs on the basis of work hour regulations imposed by their accreditors. ${ }^{225}$ Resident program applicants might rank certain programs higher than others during the "Match" process based on how they perceive certain regulatory schemes; if the most talented residents disproportionately prefer one regulatory system while "sleepy" residents gravitate toward a different system, it might become more difficult to identify the

223. See supra Section II.C (discussing the ACGME's motivation to regulate resident working conditions).

224. Id.

225. Most prospective medical residents apply to residency programs through the National Residency Matching Program (NRMP), commonly known as "The Match." Each year, approximately 16,000 U.S. medical school students and 18,000 other applicants participate in the NRMP. See Nat'l Residency Matching Program, About the NRMP, http://www.nrmp.org/about_ nrmp/index.html (last visited Dec. 8, 2006) (discussing the NRMP's history and the size of its user base). Prospective residents use the NRMP by ranking residency programs based on their preferences; similarly, residency programs rank applicants based on their own preferences. The NRMP then uses a computerized algorithm to compare these lists and "match" applicants to programs. See Nat'l Residency Matching Program, How the NRMP Process Works, http://www.nrmp.org/about_nrmp/how.html (last visited Dec. 8, 2006) (explaining how the NRMP matches applicants with programs). 
ideal regulatory system.

However, it is not likely that resident self selection would pose a problem. Applicants consider a wide range of factors during the matching process. ${ }^{226} \mathrm{~A}$ program's geographic location arguably has the greatest impact; although some applicants are willing to consider residency programs in multiple geographic areas ${ }^{227}$ they often begin the process with at least some geographic constraints. ${ }^{228}$ Some applicants believe that doing one's residency in the state or region one wishes to eventually practice will enhance post-residency employment prospects, ${ }^{229}$ while other applicants, particularly women, may strongly prefer certain geographic regions for family or other reasons. ${ }^{230}$ Applicants also place a very high value on a program's academic reputation; in fact, one recent study found that location and academic reputation were two of the five most important factors that influenced internal medicine residents to select their particular program. ${ }^{231}$ There is no reason to believe that a critical mass of applicants would place a greater value on regulatory system than program reputation or their geographical preferences. ${ }^{232}$

Furthermore, accreditors could still gather enough data to identify the ideal regulatory system even if applicant self selection took place. The typical residency program lasts between three and seven years; ${ }^{233}$ while regulatory systems may impact applicant preferences, they would not have an impact on residents who chose their residency programs before those regulatory systems were adopted. Thus, accreditors could obtain the empirical evidence they need by observing those currently enrolled in residency programs.

226. See generally KenNETH V. ISERSON, ISERSON'S GETTING INTO A RESIDENCY: A GUIDE FOR MEDICAL STUDENTS (6th ed. 2003) (discussing the residency application process, including criteria applicants should consider when evaluating programs).

227. Id. at 244-47.

228. See, e.g., Posting of Global Disrobal to http://forums.studentdoctor.net/archive/index.php/t98718.html (Jan. 12, 2004, 16:01 EST) (stating that picking geographical locations is the first step in considering different residency programs).

229. See, e.g., Posting of GreatPumpkin to http://forums.studentdoctor.net/archive/index.php/t30879. html (June 26, 2002, 15:49 EST) (suggesting the value of doing one's residency in the region one wishes to practice).

230. See, e.g., Eva M. Aagaard et al., Factors Affecting Medical Students' Selection of an Internal Medicine Residency Program, 97. J. NAT'L MED. ASs'N 1264, 1264 (2005) (indicating that geographic location is ranked third of the five biggest factors all applicants consider when selecting an internal medicine residency program, and that women rank location more highly than do men).

231. Id. at 1266.

232. For instance, there is apparently no evidence that the New York state regulations had a meaningful impact on applications to New York residency programs.

233. Reuter, supra note 40 , at 486 . 


\section{c. Creation Not Practical}

Others might argue that the creation of multiple private accreditors is not practical. Since the ACGME and its previous incarnation has been the sole graduate medical education accreditor for almost three decades, multiple private accreditors may not manifest themselves if the ACGME's monopoly is broken. Such a fear is unfounded. New accreditors would not likely find it difficult to finance their creation and continued existence. Most accreditors, including the ACGME, receive much of their funding from the accreditation fees they charge the programs they accredit. Since each accreditor would have a monopoly over graduate medical education accreditation in its region and would not have to worry about losing programs to competing accreditors, these accreditors would receive a substantial amount of guaranteed funding each year that would cover their operating costs. ${ }^{234}$

Perhaps the most serious barrier to private decentralized regulation would be opposition from the ACGME, which would lobby to retain its power. It is difficult to speculate as to how one could overcome this political barrier; one possibility might involve allowing the ACGME to retain a role as an umbrella organization of graduate medical education accreditors, much as the Council for Higher Education Accreditation (CHEA) serves as an umbrella organization for college and university accreditors. ${ }^{235}$

\section{d. Alternate Solutions}

Some may believe that solutions other than private decentralized regulation could improve the medical resident regulatory situation. For instance, one might propose that the federal government create several government-controlled and funded boards that would determine resident regulation policies within a given region. This system would not only preserve regional experimentation, but also minimize the role of state politics in the regulation process. In other words, public opinion, state medical organization lobbying, and the political considerations of state elected officials would not prevent regulations from being implemented, as they have in the past. ${ }^{236}$ However, such a system would not

234. If funding does not exist to cover an accreditor's initial start-up costs, the federal government may provide a short term loan to cover such early expenses.

235. For more information about CHEA, see Council for Higher Educ. Accreditation, CHEA Home Page, http://www.chea.org (last visited Oct. 17, 2006) (providing a general overview of CHEA and its functions).

236. As discussed earlier, several states have failed to pass legislation limiting resident work hours due to such factors. See Boodman, supra note 53; Japenga, supra note 81 (discussing state regulatory attempts in New York and elsewhere). 
possess any practical benefits over private decentralized regulation, while still retaining some of the disadvantages inherent to public entities. These boards, as an extension of the federal government, would still face the possibility of having their effectiveness limited due to the political process; for example, the boards would remain susceptible to budget cuts. Furthermore, unless these boards would also assume the ACGME's accreditation function, such a split would become economically inefficient, since both the ACGME and these boards would spend a substantial amount of time and money conducting separate site visits of residency programs. After all, the fact that the ACGME already conducts many site visits as part of its normal duties is one of the primary reasons it has been able to enforce its regulations so well relative to the state of New York.

Of course, this raises another alternate solution: Why not simply reform the ACGME from within? For instance, if the problem with the ACGME regulations is that they do not allow for experimentation, why not lobby the ACGME to create multiple alternative sets of regulations that hospitals can choose to implement at their own discretion? Unfortunately, this solution is easier said than done; medical professionals have lobbied the ACGME to change its regulations. ${ }^{237}$ The ACGME, however, has been non-responsive to these overtures, ${ }^{238}$ and has consistently rejected requests from residency program directors and other professionals that it revise its resident work hour regulations. $^{239}$

Furthermore, allowing hospitals to choose between alternate regulations would not necessarily result in natural experimentation. As the past has demonstrated, hospitals, when given the choice, will implement the regulation method that will cost the hospital the least amount of money. ${ }^{240}$ For example, if hospitals are given the choice between limiting resident work hours to eighty hours a week or requiring residents to average at least six hours of sleep per night, most hospitals would likely choose the latter regulation since the costs of complying with that regulation would be significantly lower than complying with the other regulation. ${ }^{241}$ Thus, true experimentation would not take place, and the ACGME would not have the necessary data to determine the ideal regulatory method. For natural experimentation to occur, a regulator must require all hospitals within a given region to follow one set of regulations while hospitals in

237. See Ludmerer \& Johns, supra note 49, at 1086 (discussing physician dissatisfaction with the ACGME regulations).

238. Id.

239. Id.

240. See supra Section II.B (explaining that monetary incentives and disincentives were why hospitals complied with ACGME regulations but not with New York State regulations).

241. Id. 
another region must follow a different set of regulations.

\section{Distance Learning: A Case Study in Private Decentralized Regulation}

Since private decentralized regulation of graduate medical education does not currently exist, one cannot point to real-world evidence of success or failure. However, private decentralized regulation is common in other areas of education. Most notably, colleges and universities as a whole are subject to private decentralized regulation. $^{242}$

Just as graduate medical education has faced significant turmoil due to the resident work hour debate, colleges and universities have had to struggle with their own major controversy. For the past two decades, accreditors of colleges and universities have debated whether distance learning programs, particularly entirely online universities, should be accredited, as well as how accreditors should evaluate these programs if they can be accredited. This Section contrasts how private decentralized regulators (the regional accrediting agencies that accredit colleges and universities) and a private centralized regulator (the American Bar Association, which accredits law school J.D. programs) resolved the distance learning controversy, and it applies lessons from the distance learning case study to the resident work hour controversy.

\section{College Accreditation: A Brief Overview}

Private, nongovernmental organizations accredit colleges and universities in the United States. ${ }^{243}$ Educational institution accreditation serves four primary purposes: ${ }^{244}$ assuring quality, ${ }^{245}$ facilitating access to federal funds, ${ }^{246}$ easing transfer of credits, ${ }^{247}$ and engendering private sector confidence. ${ }^{248}$ Accreditors

242. While colleges and universities as institutions are subject to private decentralized regulation, individual programs within those institutions, such as J.D. and M.D. programs, are also subject to other types of regulation, most commonly private centralized regulation. See infra Subsection IV.C.1 (providing a brief overview of the college accreditation system).

243. Council for Higher Educ. Accreditation, Accrediting Organizations in the U.S.: How Do They Operate To Assure Quality? 1 (2006), http://www.chea.org/pdf/fact_sheet_5_operation.pdf [hereinafter CHEA, Quality].

244. Council for Higher Educ. Accreditation, Profile of Accreditation 2 (2006), http://www.chea.org/pdf/fact_sheet_1_profile.pdf [hereinafter CHEA, Profile].

245. See id. ("Accreditation is the primary means by which colleges, universities and programs assure academic quality to students and the public.").

246. See id. ("Accreditation of institutions and programs is required in order for students to gain access to federal funds such as student grants and loans and other federal support.").

247. See id. ("Accreditation of institutions and programs is important to students for smooth transfer of courses and programs among colleges and universities."). 
are certified by the U.S. Department of Education (USDE); ${ }^{249}$ the USDE recognized fifty-six accreditors as of December 2002. ${ }^{250}$

One can divide accrediting agencies into two broad groups: institutional accreditors and specialty accreditors. Institutional accreditors, as the name implies, accredit entire educational institutions. ${ }^{251}$ One can further subdivide institutional accreditors into two subgroups: regional accreditors and national accreditors. ${ }^{252}$ Regional accreditors evaluate institutions in six specific clusters of states, or regions, with each regional accreditor having a monopoly over regional institutional accreditation within its own region; national accreditors evaluate institutions nationwide regardless of the institution's geographic region. ${ }^{253}$

Though the USDE makes no official distinction between regional and national institutional accreditors when it comes to eligibility for federal funds, educational institutions and employers overwhelmingly consider the regional accreditors far more prestigious and view regional accreditation as the gold standard of institutional quality. ${ }^{254}$ These perceptions are reflected in the characteristics of institutions that seek regional and national accreditation. Virtually all institutions that have received regional accreditation - over ninetyseven percent - are both degree-granting and non-profit. ${ }^{255}$ In contrast, sixty-four percent of nationally accredited institutions do not grant degrees, and seventynine percent are for-profit. ${ }^{256}$ Furthermore, many nationally accredited institutions are single-purpose schools, e.g. bible colleges and occupational training schools. ${ }^{257}$ Because few degree-granting colleges and universities pursue national accreditation, and since many colleges that are nationally accredited chose national accreditation because they could not become regionally accredited ${ }^{258}$ future mentions of institutional accreditors in this Note refers to

248. See id. ("Accredited status of an institution or program is important to employers when evaluating credentials of job applicants and providing financial support to current employees seeking additional education.").

249. Id. at 1 .

250. Id. at 2 .

251. CHEA, Quality, supra note 243 , at 1.

252. CHEA, Profile, supra note 244, at 1.

253. Id. at 2.

254. See Nathan Whiteside, Are Distance Learning Degrees Legitimate?, http://www.degree info.com/article1_2.html (last visited Oct. 17, 2006) ("The 'gold standard' would be . . . a USbased school which is regionally accredited.").

255. CHEA, Profile, supra note 244, at 1.

256. Id. at 2.

257. Id.

258. The American Military University, for instance, sought accreditation from the Distance Education Training Council (DETC), a national accreditor, after an unsuccessful attempt to achieve 
regional accreditation.

Specialty accreditors, in contrast, do not accredit entire institutions, ${ }^{259}$ but accredit specific programs within an institution. ${ }^{260}$ Specialty accreditors exist for dozens of specialties, ranging from law to funeral service to veterinary medicine. ${ }^{261}$ Unlike regional accreditors, specialty accreditors have a national reach in their specialty area. ${ }^{262}$ Thus, specialty accreditors are a form of private centralized regulation, while regional accreditors are analogous to private decentralized regulation.

\section{Challenges Caused by Distance Learning}

The growing popularity of distance learning programs has challenged both institutional and specialty accreditors. Distance learning, contrary to popular belief, is not a new phenomenon. In fact, distance learning predates the existence of most U.S. accrediting agencies. ${ }^{263}$ However, for most of its history distance learning never particularly posed a challenge for any accreditor. Until recently, distance learning was primarily identified with correspondence courses, where the student and the instructor communicate through postal mail. While a very small minority of established American universities created correspondence programs, ${ }^{264}$ the overwhelming majority of correspondence courses were run by

regional accreditation. Another institution, the University of South Africa, obtained DETC accreditation because it was ineligible for regional accreditation due to its location in a foreign country, yet still wanted recognition from a USDE-approved accreditor so that its growing number of American students could receive financial aid from the U.S. government.

259. Some exceptions apply, such as when an institution has a singular purpose and only offers one program that is in the domain of a specialty accreditor. For instance, Brooklyn Law School is accredited by the American Bar Association, a specialty accreditor, but not by a regional or national institutional accreditor. See CHEA Database, http://www.chea.org/search/search.asp (last visited Dec. 8, 2006) (search for "Brooklyn Law School").

260. CHEA, Profile, supra note 244.

261. For a complete list of specialty accreditors, see Council for Higher Educ. Accreditation, Recognized Accrediting Organizations (2006), http://www.chea.org/pdf/CHEA_USDE_AllAccred. pdf [hereinafter CHEA, List] (providing a list of all accreditors recognized by the USDE or CHEA).

262. CHEA, Profile, supra note 244, at 2.

263. For example, the University of London began to offer degrees through its distance learning program in 1858. See Univ. of London, A Brief History, http://www.london.ac.uk/history.html (last visited Oct. 17, 2006) (discussing the university's history, including the founding of its distance learning program).

264. Penn State began offering correspondence courses in 1892, primarily in agriculture. In the 1920 s the program began to offer courses over the radio, and in subsequent decades the school made courses available through public and cable television as well as video and the internet. See 
diploma mills, which engaged in little or no real teaching and literally sold unaccredited degrees through the mail for a hefty profit. ${ }^{265}$ Since almost no legitimate American universities even offered correspondence courses, let alone correspondence degrees, ${ }^{266}$ and since the overwhelming majority of correspondence schools were blatantly fraudulent and did not even attempt to obtain accreditation, ${ }^{267}$ accrediting agencies did not have to concern themselves with evaluating distance learning programs.

Technological advances in the 1980s and 90s, however, changed the face of distance learning. The popularization of the VCR during the 1980s caused a small spike in distance learning programs, with some schools, including Columbia University, offering courses and even a limited number of degrees through videotape. ${ }^{268}$ However, distance learning programs did not become popularized until the 1990s with the dawn of the Internet. Widespread Internet use, as well as ever growing demands for higher education services geared toward working professionals, ${ }^{269}$ resulted in a large increase in distance learning programs. The 1990s saw many regionally accredited universities offer not only online courses, but also degrees that one could complete entirely online. ${ }^{270} \mathrm{By}$

Penn State, Types of Courses, http://www.worldcampus.psu.edu/StudentServices_Typesof

Courses.shtml (last visited Oct. 17, 2006) (explaining distance education and providing a history of Penn State's own distance education program). Other schools offering correspondence courses during this period include the University of Chicago and the State University of Iowa. See Kristin Hirst, A Distance Learning Timeline, http://www.degreeinfo.com/timeline.html (last visited Oct. 17,2006 ) (providing a brief history of distance learning).

265. Diploma mills have existed in the United States since the Civil War era. See Christopher Bahur, Diploma Mills: Fraud in Higher Education, http:/www.degreeinfo.com/article24_1.html (last visited Oct. 17, 2006) (providing a history of diploma mills).

266. Hirst, supra note 264.

267. Bahur, supra note 265.

268. Columbia University created the Columbia Video Network in 1986, offering courses and degrees in engineering fields. Columbia Video Network, About CVN, http://www.cvn.columbia. edu/About_CVN/about_cvn.html (last visited Oct. 17, 2006).

269. In 2000, more than fifty-six percent of all college students were more than twenty-two years old, with over twenty-six percent older than thirty. Nat'l Ctr. for Educ. Statistics, Total Enrollment in All Degree-Granting Institutions by Sex, Age, and Attendance Status, http://nces.ed.gov/programs/projections/tables/table_11.asp (last visited Oct. 17, 2006). More than forty-one percent of college students in 2000 were enrolled as part time students. $I d$.

270. For more information on this phenomenon, see Risa Lieberwitz, The Corporatization of the University: Distance Learning at the Cost of Academic Freedom?, 12 B.U. PUB. INT. L.J. 73, $104-$ 06 (providing a list of many universities that created online distance learning programs during the 1990s, including Carnegie Mellon University, Columbia University, Cornell University, Duke University, the London School of Economics, McGill University, New York University, Purdue University, Stanford University, Temple University, the University of Baltimore, the University of 
2002, there were 1708 regionally accredited colleges and universities that offered distance learning programs - more than fifty-five percent of all regionally accredited institutions! ${ }^{271}$ Perhaps even more notably, several entirely online colleges and universities were founded during this period, such as Jones International University ${ }^{272}$ and Northcentral University. ${ }^{273}$

The creation of so many distance learning programs in such a very short period of time caused both regional and specialty accreditors to wrestle with many new and controversial issues. Regional accreditors had to determine whether an institution with no physical campus should be accredited, and if so, what standards should be applied relative to traditional "brick and mortar" schools. ${ }^{274}$ Furthermore, accreditors had to decide how to evaluate online programs provided by "brick and mortar" schools that were already accredited. For example, the Middle States Association of Colleges and Schools had to determine how it should evaluate Touro College, a school founded in 1971 with more than 11,000 students on its home campus in New York, ${ }^{275}$ after Touro launched an entirely online subsidiary school, Touro University International, in 1999, with all of its administrative offices in California and an enrollment of over 7000 students. ${ }^{276}$ Specialty accreditors had to make similar decisions; for instance, the American Bar Association had to determine whether online law schools, such as the for-profit and entirely online Concord Law School, were eligible for ABA accreditation. ${ }^{277}$ However, despite facing very similar issues,

California at Los Angeles, the University of Chicago, the University of Florida, the University of Maryland, the University of Michigan, the University of Toronto, and the University of Virginia).

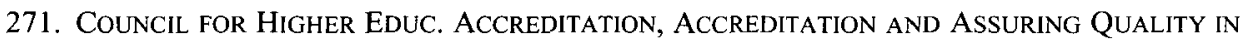
DistanCE LEARNING 3 (2002) [hereinafter CHEA, DistanCE LEARNING].

272. Jones International University was founded in 1993, and in 1999 became the first entirely online university to receive regional accreditation. Jones International Univ., History of Jones International University (2006), http://www.jiu.edu/about/history/timeline.php (last visited Oct. 17, 2006).

273. Northcentral University, a for-profit online institution with no physical campus, offers degrees ranging from bachelor to doctorate level. Northcentral Univ., NCU Fact Sheet, http://www.ncu.edu/ncu_fact_sheet.asp (last visited Oct. 17, 2006).

274. See, e.g., Kelly McCollum, Accreditation of On-Line University Draws Fire, CHron. Higher EduC., Apr. 2, 1999, at A33 (discussing the North Central Association of Colleges and Schools's controversial decision to accredit Jones International University).

275. Touro College: At a Glance, U.S. NEwS \& WORLD REP., http://www.usnews.com/ usnews/edu/college/directory/brief/drglance_10142_brief.php (last visited Dec. 8, 2006).

276. E-Learning: Touro University International (CA): General Information, U.S. NEwS \& WORLD REP., http://www.usnews.com/usnews/edu/elearning/directory/elearnla_666129.htm (last visited Dec. 8, 2006).

277. Concord Law School is a part of the Stanley Kaplan Corporation, which owns a chain of forty-one undergraduate colleges in addition to Concord Law School. See Stephen Brier \& Roy 
regional accreditors and the ABA reached two largely different conclusions.

\section{The Regional Accreditor Response to Distance Learning}

As one might expect, the six regional accreditors ${ }^{278}$ developed greatly differing evaluation standards of distance learning programs and institutions. While some accreditors embraced distance learning and online-only institutions and developed standards that some might consider too lenient, ${ }^{279}$ other accreditors subjected distance learning programs and institutions to levels of scrutiny that some may deem too harsh. ${ }^{280}$ Table One suggests some of these disparities.

Table 1: Distance Learning Disparity Across Accreditors

\begin{tabular}{|l|l|}
\hline Regional Accreditor & Schools w/ DL Programs \\
\hline Middle States Association & $59.4 \%$ \\
\hline New England Association & $28.6 \%$ \\
\hline North Central Association & $62.5 \%$ \\
\hline Northwest Association & $70.5 \%$ \\
\hline Southern Association & $58.7 \%$ \\
\hline Western Association & $23.8 \%$ \\
\hline
\end{tabular}

Rosenzweig, The Keyboard Campus; Digital Diploma Mills: The Automation of Higher Education, The Nation, Apr. 22, 2002, at 30 (discussing Stanley Kaplan and Concord Law School).

278. The six regional accreditors are the Middle States Association of Colleges and Schools, the New England Association of Schools and Colleges, the North Central Association of Colleges and Schools, the Northwest Commission on Colleges and Universities, the Southern Association of Colleges and Schools, and the Western Association of Schools and Colleges. Technically there are eight regional accreditors, since the New England Association and the Western Association have each divided themselves into two separate commissions: one that accredits senior colleges and universities and a second that accredits community colleges and vocational schools. CHEA, List, supra note 261 , at 1 . However, since both commissions are a part of the larger association, and since their policies do not differ drastically from each other, this Note treats them as one for purposes of this analysis unless otherwise noted.

279. See, e.g., Posting of Rich Douglas to http://forums.degreeinfo.com/showthread.php?s $=\mathrm{ad} 9130677 \mathrm{a} 09 \mathrm{da} 7369 \mathrm{f} 224 \mathrm{a} 788 \mathrm{e} 2 \mathrm{a} 4 \mathrm{ef} \&$ threadid=1854 (June 26, 2001, 19:36 GMT) (stating that "North Central certainly has been the most open about accrediting ... DL schools" and "Middle States has been generally positive.").

280. See, e.g., id. ("WASC has always been a toughie."); Posting of John Bear to http://forums.degreeinfo.com/showthread.php?s=ad9130677a09da7369f224a788e2a4ef\&threadid= 2741 (Oct. 29, 2001, 03:47 GMT) (stating that "the Western Association is especially difficult on nontraditional models").

281. CHEA, DistanCE LEARNING, supra note 271 , at 5. 
The most notable differences between the regional accreditors were in their attitudes toward institutions that offered only online programs with no physical campus. In this respect, one accreditor, the North Central Association, developed a reputation as extremely receptive to purely online schools. ${ }^{282}$ The North Central Association became the first regional accreditor to accredit an entirely online university when it accredited Jones International University in 1999, causing a substantial amount of controversy. ${ }^{283}$ In contrast, two other accreditors, the Southern Association and the Western Association, were perceived as hostile to the idea of accrediting online schools. ${ }^{284}$ In fact, there are several documented instances of online or mostly online schools relocating their administrative offices after failing to receive accreditation from these associations. Walden University, while not entirely a distance learning school, ${ }^{285}$ moved its administrative offices from Naples, Florida, to Minneapolis, Minnesota, so it would fall under the jurisdiction of the North Central Association, after an unsuccessful attempt at Southern Association accreditation. ${ }^{286}$ Touro University International made the very unusual move of asking the Middle States Association to include its programs under Touro College's accreditation in order to avoid seeking Western Association accreditation. ${ }^{287}$ Most recently, the American Military University, an entirely online institution, moved some of its offices across the border from Virginia to West Virginia; like Walden, it failed to achieve Southern Association accreditation and felt it would have greater success with the North Central Association. ${ }^{288}$

282. Douglas, supra note 279.

283. McCollum, supra note 274.

284. Douglas, supra note 279.

285. For example, Walden requires its doctoral students to attend academic residencies in order to "give doctoral students the opportunity to work face-to-face with faculty, staff, and other doctoral students." Walden Univ., University Services: Residencies, http://www.waldenu.edu/ c/Services/UniversityServices_389.htm (last visited Oct. 17, 2006).

286. For more information about Walden University, see Walden Univ., About Walden University, http://www.waldenu.edu/c/About/About.htm (last visited Oct. 17, 2006).

287. For more information about Touro College, see Touro Coll., About Touro College, http://www.touro.edu/general/about.asp (last visited Oct. 17, 2006). See also Posting of BillDayson to http://forums.degreeinfo.com/showthread.php?s=5b8ef5d2f24foffa0f6b6166340c02d6\&

threadid=19904 (June 16, 2005, 12:44 GMT) (discussing the accreditation status of Touro College and its various physical and online branch campuses, and observing that "Touro seems to enjoy living on the edge").

288. The American Military University (AMU) was founded in 1993 in Virginia, and it applied for Southern Association accreditation in 1998. In 1999, AMU was told that while it "met the requirements of the majority of the SACS conditions," it would not receive accreditation due to 
Each regional accreditor continued to apply different standards to distance learning programs and institutions until 2001. In that year, the regional accreditors, realizing the need for greater uniformity in this area, convened a joint committee to examine how accreditors should evaluate distance learning programs. As a result of this meeting, a set of "best practices" were codified and adopted by all of the regional accreditors. ${ }^{289}$ These best practices "constitute a common understanding of those elements which reflect quality distance education programming."290 These practices were not developed in a vacuum. Rather, they were determined after all regional accreditors discussed their individual experiences evaluating distance learning programs. ${ }^{291}$ As a result of sharing their experiences, accreditors were able to adopt the evaluation methods proven to work best and discard those that were known to be ineffective, resulting in all the regional accreditors adopting distance education evaluation policies that were not only uniform, ${ }^{292}$ but better than any one accreditor had previously enacted individually.

\section{The ABA Response to Distance Learning}

The ABA, as a specialty accreditor with monopoly power over J.D. program accreditation, ${ }^{293}$ approached the distance learning controversy differently than the regional accreditors. When faced with whether it should accredit online law

some requirements not being met. Am. Military Univ., General Information FAQs, http://web.archive.org/web/20011218233612/http://www.amunet.edu/GeneralInformation/faqs.asp (last visited Oct. 17, 2006). In 2002, AMU created a spin-off university, the American Public University, and created the American Public University System (APUS) to serve as an umbrella organization for these two institutions. APUS established its corporate offices in West Virginia, and in February 2004 APUS became a candidate for North Central Association accreditation. Am. Pub. Univ. Sys., Accreditation and Licensure, http://www.apus.edu/APUS/Accreditation/ Accreditation-and-Licensure.htm (last visited Oct. 17, 2006).

289. Best Practices for Electronically Offered Degree and Certificate Programs, https://wcet.info/services/publications/accreditation/Accrediting_BestPractices.pdf [hereinafter Best Practices].

290. Id.

291. Id.

292. $I d$.

293. Some scholars have argued that the ABA has used its monopoly power to homogenize legal education to the point where it is no longer a competitive market. See, e.g., Andrew P. Morriss, The Market for Legal Education \& Freedom of Association: Why the "Solomon Amendment" Is Constitutional and Law Schools Aren't Expressive Associations, 14 WM. \& MARY BILL RTS. J. 415 (2005) ("The critical point is this: the legal education market is not a competitive market. The lack of competition should make courts skeptical of the behavior of what gives every appearance of being a cartel."). 
schools such as Concord Law School, ${ }^{294}$ the ABA's answer was very simple and straightforward: No. ${ }^{295}$ Unlike regional accreditors, who allowed experimentation with distance learning and discovered that schools can deliver many quality degree programs through electronic media, ${ }^{296}$ the ABA has taken a very hard-line approach and has retained accreditation guidelines that make it very difficult for online law schools to become established, such as requiring physical classrooms and libraries. ${ }^{297}$ In fact, the ABA has gone so far as to prohibit law schools from granting credit for online or correspondence study, ${ }^{298}$ although this rule has recently been relaxed to allow students to complete a maximum of twelve credits online. ${ }^{299}$ The ABA has justified such draconian measures by arguing that online learning does not allow for proper training $\mathrm{g}^{300}$ - a conclusion obviously in conflict with many educational administrators, ${ }^{301}$ as well as the regional accreditors. ${ }^{302}$

Such a hard-line conservative reaction is not unusual for the ABA; the organization had similar harsh restrictions against for-profit law schools, until a U.S. Department of Justice lawsuit and subsequent settlement by the ABA forced the accreditor to change its practices. ${ }^{303}$ The ABA's stance toward Concord and other online law schools, then, is only "the latest example of how the ABA's rigid and outdated standards operate to stifle innovation." ${ }^{\text {, }} 04$ As a national

294. For more information about Concord Law School, see Concord Law Sch., Dean's Message, http://www.concordlawschool.com/info/custom/concord/schoolinfo/message.asp (last visited Oct. 17, 2006) (providing a brief description of the institution).

295. Geoffrey Gagnon, Join 'Em, LEGAL AFF., May-June 2004, available at http://www.legal

affairs.org/issues/May-June-2004/scene_gagnon_mayjun04.msp (last visited Dec. 8, 2006).

296. Best Practices, supra note 289.

297. Gagnon, supra note 295.

298. Id.

299. See Am. Bar Ass'n, Standard 306: Distance Education, http://www.abanet.org/legaled/ distanceeducation/Standard306.doc (last visited Oct. 17, 2006) (explaining the ABA's position on distance education).

300. Julia Scheeres, Virtual Degrees Virtually Tough, WIRED NEws, Aug. 28, 2002, http://www.wired.com/news/school/0,1383,54734,00.html.

301. For example, former Harvard University President Lawrence Summers "emphasized the importance of embracing the marriage of education and technology" in his 2005 commencement speech. See Paul D. Rosevear, The Ivy League Goes Online, AOL REs. ONLINE, Jan. 25, 2006, http://encarta.msn.com/encnet/Departments/elearning/?article=IvyLeagueOnline (providing many examples of elite colleges and universities embracing distance learning).

302. Best Practices, supra note 289.

303. For a concise summary of the lawsuit, see Robert J. Salzer, Note, JurisDoctor.com: Are Full-Time Internet Law Schools the Beginning of the End for Traditional Legal Education?, 12 COMMLAW CONSPECTUS 101, 111-12 (2004).

304. Herb D. Vest, Felling the Giant: Breaking the ABA's Stranglehold on Legal Education in America, 50 J. Legal EduC. 494, 501 (2000). 
monopoly, the ABA, unlike the regional accreditors, is under no obligation to change its policies; this same monopoly power also prevents the ABA from experimenting with distance learning and seeing its results first hand. While the ABA claims that distance learning cannot properly train lawyers, ${ }^{305}$ at the time such regulations were made the ABA had no way of knowing whether such a belief was actually true, since it had not allowed for any lawyers to obtain training through online law schools and then attempt the bar exam or practice law. ${ }^{306}$ Since no experimentation took place, no one can point to any evidence to find fault with the ABA's policies, thus perpetuating the status quo.

\section{Parallels to the Resident Working Hours Controversy}

Much of the distance learning experience applies to the resident work hour regulation debate. The ABA shares many similarities with the ACGME, most notably its monopoly status over accreditation in its field, which it uses to stifle innovation and ensure homogeneity within legal education. ${ }^{307}$ Just as the ACGME has not responded to evidence showing that work hour limits may not promote patient safety, the ABA has ignored evidence showing that quality degree programs can take place through distance learning. ${ }^{308}$ Furthermore, both

305. Scheeres, supra note 300.

306. While it is true that Concord Law School graduates are eligible to take the California Bar Exam, the majority of Concord students enroll for personal enrichment without the intention of taking a bar exam, since they are unable to take the bar exam in their own jurisdictions. (Though Concord has more than 1800 students enrolled, only 660 have taken the First Year Law Student Examinations required for students of non-ABA accredited schools who wish to take the Bar. Concord Law School, School Information: Institutional Assessment Findings, $\mathrm{http} / /$ www.concordlawschool.com/info/custom/concord/schoolinfo/assessment_findings.asp (last visited Dec. 8, 2006).) Furthermore, Concord's lack of ABA accreditation inherently prevents it from competing for the best students, since students who do wish to take the bar and become lawyers after graduation will naturally gravitate toward ABA-accredited schools, which will allow them to take the bar exam in any jurisdiction as well as provide them with greater employment opportunities. Since many of the students Concord currently attracts who do take the bar exam are those who would not have gotten into an ABA school, it is not really fair to use Concord's California bar passage rates as an indictment on the potential of distance learning, since many such individuals would likely have failed if they had attended a traditional law school. See Scheeres, supra note 300.

307. See Harry First, Competition in the Legal Education Industry, 53 N.Y.U. L. REv. 311, $327-$ 28 (1978) (arguing that the ABA has used its monopoly power to force law schools to adopt the "elite-preference model" of legal education).

308. See, e.g., Thomas J. Balcezak et al., A Web-based Risk Management and Medical-Legal Curriculum for Graduate Medical Education, 25 J. Biocommunication 2, 4 (1998) ("Those residents who first browsed the educational module scored significantly higher on the quiz $(81 \%)$ 
organizations have prevented natural or controlled experimentation from taking place by using their monopoly power to institute nationwide regulations. ${ }^{309}$

than those who did not (62\%)."); Tina M. Day et al., The Effects of World Wide Web Instruction and Traditional Instruction and Learning Styles on Achievement and Changes in Student Attitude in a Technical Writing in Agricommunication Course, 39 J. AGRIC. EDUC. 65 (1998) ("[S]tudents who completed a writing course on the web exhibited higher achievement scores than those in conventional instruction in the area of communication writings."); John Dutton et al., Do Online Students Perform as Well as Lecture Students?, 90 J. EngineERING Educ. 131, 131 (2001) ("These results demonstrate that online students can perform at least as well as traditional students."); Scott D. Johnson et al., Comparative Analysis of Learner Satisfaction and Learning Outcomes in Online and Face-to-Face Learning Environments, 11 J. INTERACTIVE LEARNING RES. 29, 29 (2000) ("[T]here was no difference between the two course formats in several measures of learning outcomes."); G. Klass \& L. Crothers, An Experimental Evaluation of Web-Based Tutorial Quizzes, 18 SOC. SCI. COMPUTER REV. 508, 508 (2000) ("We find no significant differences on post test scores between students who were assigned Web quizzes and those who were not."); L.A. Lockard, The Impact of Technology Plans on Students' and Teachers' Learning, 29 TECH. HorIzONS EduC. J. 18, 24 (2001) (finding that integrating technology improved graduation rates); Krisanna Machtmes \& J. William Asher, A Meta-Analysis of the Effectiveness of Telecourses in Distance Education, 11 AM. J. DistanCE EdUC. 29, 43 (2000) ("There does not appear to be a difference in achievement between distance and traditional learners."); M.S. Nessler et al., Professional Socialization of Baccalaureate Nursing Students: Can Students in Distance Nursing Programs Become Socialized?, 40 J. NURSING EDUC. 293, 300 (2001) ("[N]ursing students near completion in distance nursing programs had significantly higher scores on two measures of socialization than did campus-based nursing students."); Alan F. Smeaton \& Gary Keogh, An Analysis of the Use of Virtual Delivery of Undergraduate Lectures, 32 COMPUTERS \& EDUC. 83, 92 (1999) ("The results in this paper have shown that when virtual lectures are used in place of traditional delivery methods there is no significant difference in attainment levels as measured by end of year examination marks."); K.E. Umble et al., Effects of Traditional Classroom and Distance Continuing Education: A Theory-Driven Evaluation of a Vaccine-Preventable Disease Course, 90 AM. J. PuB. HEALTH 1218,1222 (2000) ("No significant difference was found between the increases in knowledge and self-efficacy for participants in the classroom and broadcast courses, both immediately following and 3 months after the course."); Dan Carnevale, What Matters in Judging Distance Teaching? Not How Much It's Like a Classroom Course, ChroN. HiGHER EduC., Feb. 21, 2001, available at http://chronicle.com/free/2001/02/2001022101u.htm ("The delivery mode we know for a fact does not impact the learning."); Debbie Goldberg, Teaching Online, WASH. Post, Apr. 5, 1998, at R04 ("[T]he off-campus students perform just as well as their on-campus counterparts in the same courses."); James V. Koch, How Women Actually Perform in Distance Education, CHRON. Higher EDuC., Sept. 11, 1998, at A60 ("[T]wo studies of students in Indiana ... found no statistically significant difference."); Dennis A. Trinkle, Distance Education: A Means to an End, No More, No Less, Chron. Higher Educ., Aug. 6, 1999, at A60 ("[T]here is clear evidence that distance education can be as successful as classroom-based instruction, if not more so.").

309. See Vest, supra note 304, at 501 ("[I]f you try to offer legal education that is outside the box, such as an affordable, convenient, online program, you are likely to end up without ABA 
If the ACGME's national monopoly over graduate medical education accreditation (or the ABA's monopoly over legal education) were replaced with a private decentralized system, like regional accreditation, experimentation would take place. Private decentralized graduate medical education accreditors would approach the resident work hour controversy just as regional accreditors approached the distance learning issue: at first, each accreditor would create its own policies using its best judgment, and then after sufficient evidence accumulated, the accreditors would gather together to create a set of "best practices" for the sake of uniformity. Through obtaining a significant amount of data, as well as firsthand observations, the private decentralized accreditors would select the best of all the attempted regulatory systems in order to create an effective regulatory system that would best enhance patient safety while at the same time retaining the support of residency program directors.

\section{CONCLUSION}

The resident work hour limit controversy has spurred considerable debate, both over what limits, if any, should be instituted, as well as over which organization should determine those limits. The free market's failure to account for the patient safety externality, as illustrated by the death of Libby Zion, has shown that some form of regulation is necessary; however, observable actions by state governments and the ACGME have shown that neither can serve as an ideal regulator. Though some have lobbied for the federal government to intervene, ${ }^{310}$ it is doubtful that the federal government's involvement would improve the situation.

Private decentralized regulation appears to be the best solution to the work hour limit debate. By eliminating the ACGME monopoly over graduate medical education and entrusting multiple regional accreditors with the ACGME's current functions, individual accreditors would experiment with different policies, with an ideal policy or combination of policies eventually manifesting itself. As demonstrated by the distance learning case study, private decentralized regulation does work in practice, and it has brought about better results than private centralized regulation. It is likely, therefore, that a private decentralized approach to the regulation of graduate medical education would best further the goal of patient safety as well as provide the best framework for solving future graduate medical education controversies.

approval.").

310. See, e.g., Am. Med. Student Ass'n, supra note 208. 